OPEN ACCESS

Edited by:

Zhanjun Jia,

Nanjing Medical University, China

Reviewed by:

Rujun Gong,

University of Toledo Medical Center,

United States

Mi Bai,

Nanjing Medical University, China

${ }^{*}$ Correspondence:

Hui-Yao Lan

hylan@cuhk.edu.hk

Xu-Sheng Liu

liuxusheng@gzucm.edu.cn

Specialty section:

This article was submitted to Renal and Epithelial Physiology, a section of the journal

Frontiers in Physiology

Received: 23 March 2021

Accepted: 06 April 2021

Published: 13 May 2021

Citation:

Gu $Y$-Y, Dou J-Y, Huang $X-R$

Liu X-S and Lan H-Y (2021)

Transforming Growth Factor- $\beta$ and Long Non-coding RNA in Renal

Inflammation and Fibrosis.

Front. Physiol. 12:684236.

doi: 10.3389/fphys.2021.684236

\section{Transforming Growth Factor- $\beta$ and Long Non-coding RNA in Renal Inflammation and Fibrosis}

\author{
Yue-Yu Gu1,2, Jing-Yun Dou1,3, Xiao-Ru Huang ${ }^{2,4}$, Xu-Sheng Liu' ${ }^{1 *}$ and Hui-Yao Lan ${ }^{2,5 *}$ \\ 1 Guangdong Provincial Key Laboratory of Clinical Research on Traditional Chinese Medicine Syndrome, Department \\ of Nephrology, Guangdong Provincial Hospital of Chinese Medicine, Second Affiliated Hospital, Guangzhou University \\ of Chinese Medicine, Guangzhou, China, ${ }^{2}$ Department of Medicine and Therapeutics, Li Ka Shing Institute of Health \\ Sciences, The Chinese University of Hong Kong, Hong Kong, China, ${ }^{3}$ Department of Nephrology, Weihai Hospital \\ of Traditional Chinese Medicine, Weihai, China, ${ }^{4}$ Guangdong-Hong Kong Joint Laboratory for Immunity and Genetics \\ of Chronic Kidney Disease, Guangdong Academy of Medical Sciences, Guangdong Provincial People's Hospital, \\ Guangzhou, China, ${ }^{5}$ Guangdong-Hong Kong Joint Laboratory for Immunity and Genetics of Chronic Kidney Disease, \\ The Chinese University of Hong Kong, Hong Kong, China
}

Renal fibrosis is one of the most characterized pathological features in chronic kidney disease (CKD). Progressive fibrosis eventually leads to renal failure, leaving dialysis or allograft transplantation the only clinical option for CKD patients. Transforming growth factor- $\beta$ (TGF- $\beta$ ) is the key mediator in renal fibrosis and is an essential regulator for renal inflammation. Therefore, the general blockade of the pro-fibrotic TGF- $\beta$ may reduce fibrosis but may risk promoting renal inflammation and other side effects due to the diverse role of TGF- $\beta$ in kidney diseases. Long non-coding RNAs (IncRNAs) are RNA transcripts with more than 200 nucleotides and have been regarded as promising therapeutic targets for many diseases. This review focuses on the importance of TGF- $\beta$ and IncRNAs in renal inflammation, fibrogenesis, and the potential applications of TGF$\beta$ and IncRNAs as the therapeutic targets and biomarkers in renal fibrosis and CKD are highlighted.

Keywords: long non-coding RNA, renal fibrosis, inflammation, TGF- $\beta$, SMADs, molecular therapy

\section{INTRODUCTION}

Chronic kidney disease (CKD) has become a significant public health problem with the rising mortality and morbidity over the past three decades (Provenzano et al., 2019). Renal fibrosis is one of the most prominent pathogenic features and the best predictor for CKD progression (Majo et al., 2019). Triggered by the initial renal insults, the fibrotic process evokes to establish repairs. However, as severe or persistent injuries prolong, renal resident cells, together with infiltrating cells, may contribute to the initiation and progression of fibrosis with excessive deposition of extracellular matrix (ECM) in the glomerulus, tubulointerstitium, and vasculature (Glassock et al., 2017). Moreover, unresolved renal inflammation could also trigger the fibrotic process by releasing pro-fibrotic growth factors, cytokines, and chemokines (Chung and Lan, 2011; Meng et al., 2014). Injuries from mesangial cells, endothelial cells (ECs), podocytes, tubular epithelial cells (TECs), and inflammatory cells could also lead to renal glomerular and interstitial fibrosis (Figure 1). Progressive renal fibrosis and inflammation can then impair the function of nephrons and results in albuminuria and the reduction of eGFR. Renal fibrosis culminates in renal failure, well known as end-stage renal disease (ESRD) (Liu, 2011). 


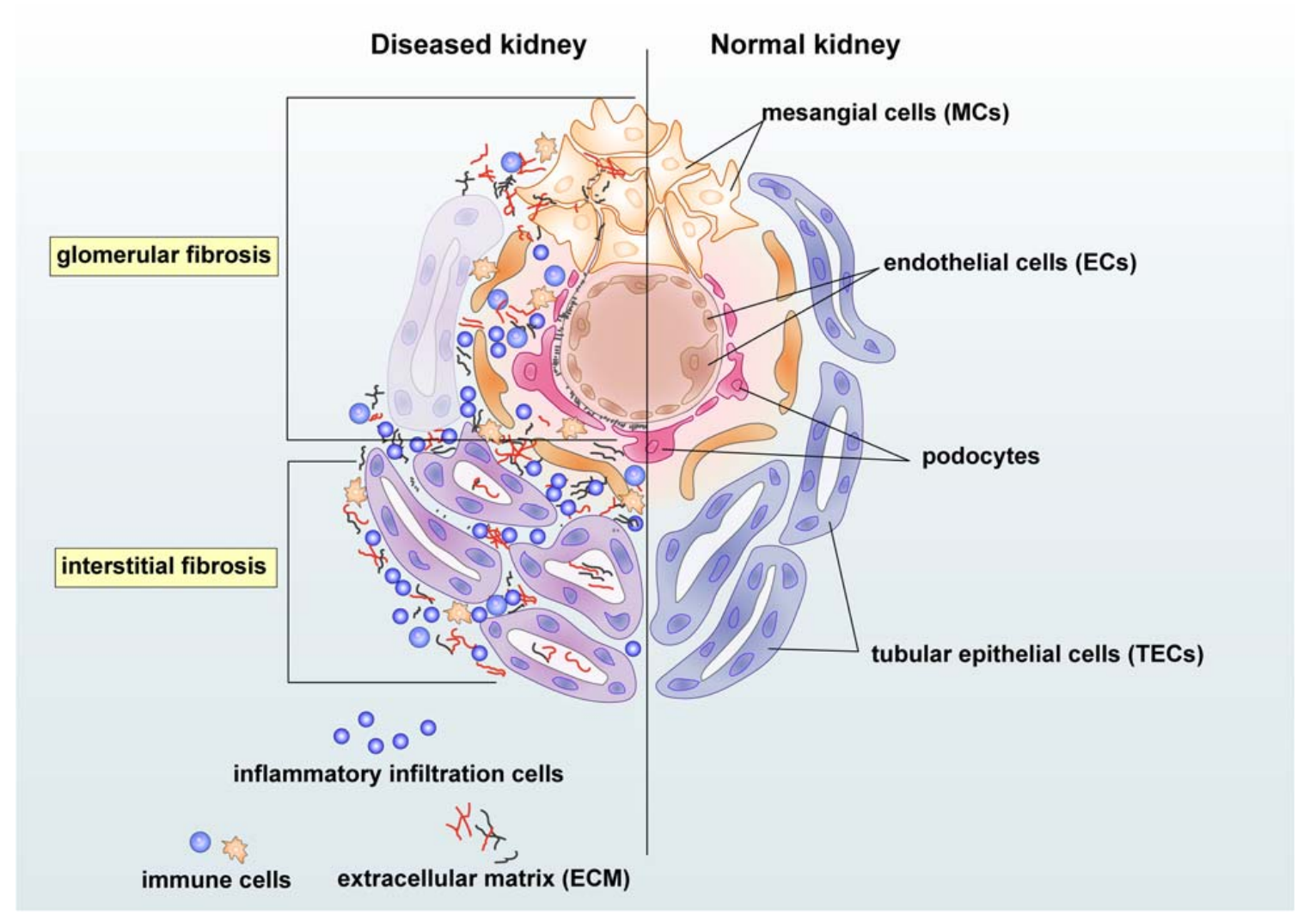

FIGURE 1 | Renal intrinsic and inflammatory cells in glomerular and interstitial fibrosis during kidney injury. Damaged mesangial cells (MCs), endothelial cells (ECs), and podocytes are essential in the glomerular fibrosis. The mesangial cell may produce pro-fibrotic and pro-inflammatory growth factors and cytokines and enhance proliferation to cause deposition of the mesangial matrix. Damages on endothelial cells and podocytes may lead to albuminuria and endothelial dysfunction in chronic kidney disease (CKD). Injured tubular epithelial cells (TECs) may produce pro-fibrotic and pro-inflammatory factors, resulting in the accumulation of extracellular matrix (ECM) and inflammatory cells in the tubulointerstitium area. Immune cells, including macrophages and T cells, may participate in renal fibrosis by producing growth factors and becoming collagen-producing myofibroblasts under the regulation of transforming growth factor- $\beta$ (TGF- $\beta$ )/Smad3 signaling.

Transforming growth factor- $\beta$ (TGF- $\beta$ ) is a primary pathophysiologic cytokine that instigates the process of fibrosis (Meng et al., 2016a). TGF- $\beta$ can induce transcription of fibrotic products such as $\alpha$-SMA and collagens by canonical and non-canonical signaling pathways. Fibrotic mediators include angiotensin II (Ang II), reactive oxygen species (ROS), as well as advanced glycation end products (AGEs) that may activate individual pathways to crosstalk with TGF- $\beta$ /Smad signaling to regulate renal fibrosis and inflammation (Chung et al., 2010; Lan, 2011). However, current anti-fibrotic therapies by targeting TGF- $\beta$ are ineffective with unexpected side effects, underscoring the complexities of the TGF- $\beta$ signaling pathway (Yoshimura and Muto, 2011; Gu et al., 2020a).

With the new technologies of high-throughput assays, we can now update our understanding of the genomes. The transcriptomic studies have demonstrated that the vast majority of the genomes in mammals produce large numbers of nonprotein-coding RNAs (ncRNAs) (Quinn and Chang, 2016). These ncRNAs are classified into long non-coding RNAs (lncRNAs), microRNAs (miRNAs), small interfering RNAs (siRNAs), small nuclear RNAs (snRNAs), small nucleolar RNAs (snoRNAs), and PIWI-interacting RNAs (piRNAs) (Van der Hauwaert et al.,
2019). Of these ncRNAs, lncRNAs are characterized as RNAs being transcribed over 200 nucleotides in length. They have been considered the major players in fibrotic diseases's pathogenesis due to their tissue and cell-type specificity and the regulations on DNAs, RNAs, and proteins (Jiang and Zhang, 2017). Of note, many TGF- $\beta /$ Smad3-regulated IncRNAs have been reported as essential mediators in the process of renal fibrosis and inflammation (Tang et al., 2017, 2018a,b).

In this review, the underlying mechanistic signaling pathways by which TGF- $\beta$ and lncRNAs drive renal fibrosis are to be discussed. The developments of biomarkers and therapeutic potential for renal inflammation and fibrosis by targeting TGF$\beta /$ Smad signaling and lncRNAs are also described.

\section{DIVERSE ROLES OF TGF- $\beta$ /SMAD SIGNALING PATHWAY IN RENAL INFLAMMATION AND FIBROSIS}

Transforming growth factor- $\beta$ is a pleiotropic cytokine that plays diverse roles in a wide range of biological and pathological processes. Indeed, TGF- $\beta$ acts as either deleterious or protective 
functions in kidney diseases (Lopez-Hernandez and LopezNovoa, 2012). TGF- $\beta$ may induce renal fibrosis by canonical and non-canonical signaling pathways (Lan and Chung, 2012; Isaka, 2018). Besides, TGF- $\beta$ promotes renal fibrosis by stimulating ECM accumulation and alternatively activating the pro-fibrotic immune cells, facilitating the transitions from various cell types into pro-fibrotic cells (Gu et al., 2020b). Therefore, understanding the diverse roles of TGF- $\beta$ is of utmost importance in the development of anti-fibrotic therapies.

Transforming growth factor- $\beta$ is a well-characterized member that belongs to the TGF- $\beta$ superfamily. Among three isoforms of TGF- $\beta$, TGF- $\beta 1$ is considered the pro-fibrotic molecule that drives the fibrotic process via canonical and non-canonical signaling pathways (Lodyga and Hinz, 2019). In particular, high expression of TGF- $\beta 1$ is observed in most, not all progressive forms of human and rodent kidney diseases (Kopp et al., 1996; Fan et al., 1999; Lan, 2012b; Lan and Chung, 2012), demonstrating the pathogenic role for TGF$\beta 1$ in CKD. To induce transcriptions of target genes, likely as $\alpha$-SMA and collagens, the latent TGF- $\beta 1$ becomes active and binds to TGF- $\beta$ receptors, promoting the transduction of a series of Smad proteins to regulate fibrogenesis (Derynck and Zhang, 2003). Regarding the downstream TGF- $\beta /$ Smad signaling, although the functions of Smad2 and Smad4 have been well studied (Tsuchida et al., 2003; Ju et al., 2006; Meng et al., 2012; Morishita et al., 2014; Loeffler et al., 2018), their mechanistic roles are diverse and unclear due to the limited availability of animal models, which still warranted for further exploration.

It is widely acknowledged that Smad3 is pro-fibrotic, while Smad2 and Smad7 are anti-fibrotic. Smad3 is highly activated in a wide range of renal disease; evidence on animal models suggest that the inhibition or blockade of Smad3 may reduce the fibrotic response (Wang et al., 2006; Yang et al., 2009, 2010; Li et al., 2010; Zhou et al., 2010; Liu et al., 2012; Zhang et al., 2018). By contrast, the function of Smad2 and Smad7 is protective, which negatively regulates the TGF$\beta / \mathrm{Smad} 3$ signaling in renal fibrosis and inflammation (Lan, 2008, 2012a; Chen et al., 2011). Many studies support this finding, showing that overexpression of Smad7 improves renal fibrogenesis in obstructive, diabetic, hypertensive, toxin-induced nephropathy and autoimmune crescentic glomerulonephritis ( $\mathrm{Li}$ et al., 2002; Lan et al., 2003; Hou et al., 2005; $\mathrm{Ng}$ et al., 2005; Ka et al., 2007; Chung et al., 2009; Liu et al., 2013, 2014; Dai et al., 2015) by inhibiting the TGF- $\beta /$ Smad3 and $\mathrm{NF}-\kappa \mathrm{B}$ signaling pathways. However, the contradictory findings have also reported that the overexpression of Smad7 could promote TGF- $\beta$-driven apoptosis in podocytes (Schiffer et al., 2001, 2002). Collectively, although restoring the imbalance between Smad3 and Smad7 may serve as an ideal therapy to halt the fibrotic process (Nie et al., 2014; Zhao et al., 2014, 2016; Meng et al., 2015; Du et al., 2018b), Smad3 and Smad7 also serve as the vital downstream molecules in other signaling pathways. Therefore, new specific targets should be sought.

Transforming growth factor- $\beta$ may also be produced by damaged renal intrinsic cells or immune cells in acute and
CKDs, thus promoting the transition of tubular cells into myofibroblasts (Mack and Yanagita, 2015). Myofibroblasts produce fibronectin and collagens and contribute to ECM accumulation (Yuan et al., 2019). Based on current studies, the sources of myofibroblast origins include pericytes ( $\mathrm{Wu}$ et al., 2013), renal resident fibroblasts, tubular epithelial cellmyofibroblast transition (EMT) (Iwano et al., 2002), endothelial cell-myofibroblast transition (EndoMT) (Zeisberg et al., 2008) and bone marrow-derived macrophage-myofibroblast transition (MMT) (Fan et al., 1999; Meng et al., 2016b; Wang et al., 2017). TGF- $\beta /$ Smad signaling pathway tightly regulates these transitions.

To halt the fibrotic process, strategies to inhibit the function of TGF- $\beta$ include the utilization of neutralizing antibodies (Border et al., 1990), small molecule inhibitors against TGF- $\beta$ receptors (Bonafoux and Lee, 2009), latent form of TGF- $\beta$ (Huang et al., 2008a,b) and antisense oligonucleotides to TGF$\beta 1$ (March et al., 2018). These findings have conferred a vital pathological role of TGF- $\beta$ in renal inflammation and fibrosis, implying the urgent need for anti-TGF- $\beta$ therapy.

\section{THERAPEUTIC EFFECT OF ANTI-TGF- $\beta$ TREATMENT ON KIDNEY DISEASES}

Anti-TGF- $\beta$ therapy is an issue of considerable debate. On the one hand, TGF- $\beta$ is the crucial mediator that regulates fibrosis in all organs, especially in kidneys (Györfi et al., 2018). On the other hand, TGF- $\beta$ regulates a wide range of biological and pathological processes and acts as essential roles in the immune cells, such as macrophages, conventional and unconventional $\mathrm{T}$ cells (Meng, 2019; Gu et al., 2020a). Over the past decades, a number of therapeutic drugs and clinical trials for the treatment of CKD targeting TGF- $\beta$ have further revealed the underlying mechanisms and renewed our understanding of TGF- $\beta$ signaling (Ruiz-Ortega et al., 2020).

Targeting on the TGF- $\beta$ family, LY2382770 and fresolimumab have proven no efficacy on improvements in neither proteinuria, eGFR, nor serum creatinine in focal and segmental glomerulosclerosis (FSGS) and diabetic nephropathy (DN) (Trachtman et al., 2011; Vincenti et al., 2017; Voelker et al., 2017). Besides, various side effects induced by blocking TGF- $\beta$, including herpes zoster, skin lesions, pustular rash, bleeding events, and cancers, have demonstrated the awkward situation of the anti-TGF- $\beta$ therapies. Hopefully, with the rapid development of pharmacology, a promising synthetic anti-TGF- $\beta$ agent, pirfenidone, is proven to improve the eGFR decline in patients with DN and FSGS (Cho et al., 2007; Sharma et al., 2011). Further studies and clinical trials on pirfenidone's renal protective effects are still ongoing (NCT02689778, NCT02408744, and NCT00001959).

Nevertheless, the by-effects such as gastrointestinal disorders and photosensitive dermatitis of pirfenidone are inevitable, raising safety concerns to the clinical application of antiTGF- $\beta$ therapies. Current anti-TGF- $\beta$ therapies have limited effectiveness, underscoring the urgent need to develop specific therapeutic targets to halt the progression of renal fibrosis. 


\section{THE EMERGING ROLE OF LONG NON-CODING RNAS IN RENAL INFLAMMATION AND FIBROSIS}

The genomic and transcriptional landscape is far more complicated than we previously appreciated. With the development of large-scale transcriptome analyses, we have now acknowledged that the vast majority of genomic sequence is transcribed into a group of lncRNAs (Hangauer et al., 2013). However, these lncRNAs were initially ignored as "transcriptional noise" or "evolutionary debris," dating from the 1970s (Ohno, 1972). In the 1990s, the functions of some classically defined lncRNAs are discovered, such as $\mathrm{X}$ inactive specific transcript (XIST) in X chromosome inactive specific, raising the possibility that lncRNAs may play an essential role in cellular biology and disease (Brockdorff et al., 1991; Brown et al., 1991). Of note, the number of identified lncRNAs is rapidly rising to date. Based on the GENCODE ${ }^{1}$ (version 33), 17952 lncRNA and 19957 protein-coding genes have been identified in the human genome, but the functions of lncRNAs in renal development and diseases remain largely unknown. In the context of lncRNA function in kidney diseases, lncRNAs may act as scaffolds, decoys, or guides to control the recruitment or dismissal of chromatin-modifying complexes.

Although lncRNAs produce in deficient amounts, their expression patterns are highly restricted to specific cell types, tissue, developmental stage, or disease state, suggesting the distinctive roles of lncRNAs in different physiological or pathological contexts (Batista and Chang, 2013; Flynn and Chang, 2014). Pathologically, the fibrotic and inflammatory processes in the kidneys may be triggered by a wide range of renal injuries in the attempt to establish tissue repair. Pathological hallmarks include TGF- $\beta$ activation, myofibroblast differentiation and transition, ECM deposition, and inflammatory responses. Of note, TGF- $\beta$ is a master regulator of immune cell trades that it correlates closely with the development, homeostasis, and differentiation of immune cells such as T cells (Li and Flavell, 2008). T cells are the predominant players in TGF- $\beta$-driven renal fibrosis and inflammation (Kinsey and Okusa, 2014; Ludwig-Portugall and Kurts, 2014; Hu et al., 2016). The hematopoietic-specific TGF- $\beta$ and cytokines produced by inflammatory immune cells may activate innate and acquired immune response (Gu et al., 2020b). These may well be associated with the functions of lncRNAs in renal inflammation. For instance, lncRNAs may act as mediators in lupus nephritis pathogenesis to regulate inflammation and apoptosis of renal cells (Xue et al., 2017; Liao et al., 2019; Chen et al., 2020).

Nevertheless, lncRNAs take part in the fibrotic or inflammatory transcriptional regulation by direct interactions with RNA polymerase II (Pol II), transcription factors (TFs), and other regulators. Furthermore, some lncRNAs may act as competing endogenous RNAs (ceRNAs), which play the competitive role as the sponges to bind with miRNAs and reduce the concentration of fibrotic or inflammatory miRNAs,

${ }^{1}$ http://www.gencodegenes.org therefore competing with these miRNAs in binding to their target mRNA transcripts.

As previously mentioned, the group of lncRNAs identified in kidneys is highly specific to cell type or disease state. Studies carried out over these years have identified a group of anti- or pro-fibrotic and inflammatory lncRNAs in diabetic, acute and chronic renal diseases (Tang et al., 2017, 2018a; Ren et al., 2019; Gu et al., 2020c) (Table 1).

For example, hyperglycemia is one of the most driving forces in renal fibrosis. Zhang et al. has revealed the anti-fibrotic effect of lncRNA growth arrest-specific transcript (GAS5) in the progression of DN. IncRNA GAS5 may downregulate the expression of pro-inflammatory MMP9 by recruiting EZH2 to the MMP9 promoter region, therefore inhibiting renal interstitial fibrosis and inflammatory (Zhang et al., 2020a). IncRNA CRNDE also interacts with miR-181a-5p to to protect sepsisinduced AKI from apoptosis (Wang et al., 2020a). Moreover, overexpression of lncRNA CCAT1 may down-regulate miR-155, thus inhibiting inflammation and promoting proliferation ( $\mathrm{Lu}$ et al., 2020). LncRNA zinc finger E-box binding homeobox1antisense RNA 1 (ZEB1-AS1) provides a binding site in its promoter region for p53. It may promote $\mathrm{H} 3 \mathrm{~K} 4 \mathrm{me} 3$ histone modification on ZEB1 promoter to exhibit anti-fibrotic effect (Wang et al., 2018a). In the context of fibrosis, the function of lncRNA metastasis-associated lung adenocarcinoma transcript 1 (MALAT1) has been well-studied in cardiac and in hepatic fibrosis (Jiang et al., 2019; Riaz and Li, 2019; Che et al., 2020). MALAT1 has caught much attention in renal diseases for its anti-inflammatory effect in AKI. The expression of LncRNA 1700020I14Rik tends to decrease under high glucose conditions, but the overexpression of LncRNA 1700020I14Rik exerts an antifibrotic effects by inhibiting cell proliferation and regulating the miR-34a-5p/Sirt1/HIF-1 $\alpha$ pathway (Li et al., 2018). Moreover, IncRNA CYP4B1-PS1-001 significantly reduces in the early stage of $\mathrm{DN}$; the proliferation and fibrosis of mesangial cells are reversed as the overexpression of CYP4B1-PS1-001 regulates the ubiquitination and degradation of Nucleolin (Wang et al., 2016a, 2018c). ENSMUST00000147869 is significantly downregulated in the DN model. Overexpression of ENSMUST00000147869 may inhibit fibrosis and proliferation of mesangial cells by the possible regulation of the Cyp4a12a gene (Wang et al., 2016b). To interact with miRNAs and proteins in podocytes, pericytes, or TECs, lncRNAs such as taurine upregulated gene 1 (TUG1) (Zhao et al., 2019; Cao et al., 2020a,b), Rian (Bijkerk et al., 2019), 3110045C21Rik (Arvaniti et al., 2016) also function as antifibrotic lncRNA to participate in the pathogenesis of systematic erythematosus lupus (SLE), ischemia-reperfusion injury and obstructive nephropathy, respectively.

Studies on pro-fibrotic lncRNAs are shown in Table 2. LncRNA myocardial infarction-associated transcript (Miat) has been identified to function as miRNA sponges in TECs and pericytes, thus regulating their transitions into myofibroblast (Bijkerk et al., 2019; Wang et al., 2020b). In diabetes-induced renal injury, lncRNA nuclear enriched abundant transcript 1 (NEAT1) is found to be increased in the serum of DN patients. A further mechanistic study has revealed that lncRNA NEAT1 may progress the development of DN by sponging miR-23c. 
TABLE 1 | Anti-fibrotic or anti-inflammatory long non-coding RNAs (IncRNAs) in renal diseases.

\begin{tabular}{|c|c|c|c|c|c|}
\hline IncRNA & Model & Mechanism/target & Pathological output(s) & Year & References \\
\hline GAS5 & STZ-induced DN and rat & $\begin{array}{l}\text { Recruits EZH2 to the promoter region } \\
\text { of MMP9 }\end{array}$ & $\begin{array}{l}\text { Anti-fibrotic; } \\
\text { anti-inflammatory }\end{array}$ & 2020 & Zhang et al., 2020a \\
\hline CRNDE & Sepsis-induced AKI, rat, and TECs & $\begin{array}{l}\text { Regulation of miR-181a-5p/PPAR } \alpha \\
\text { pathway }\end{array}$ & Anti-inflammatory & 2020 & Wang et al., 2020a \\
\hline CCAT1 & LPS-induced AKI mice and TECs & $\begin{array}{l}\text { Overexpression of CCAT1 sequesters } \\
\text { miR-155 and leads to upregulation of } \\
\text { SIRT1 and TECs damage }\end{array}$ & Anti-inflammatory & 2020 & Lu et al., 2020 \\
\hline \multirow[t]{2}{*}{ TUG1 } & SLE patient serum and SLE mouse & / & $\begin{array}{l}\text { Anti-fibrotic; } \\
\text { anti-inflammatory }\end{array}$ & 2020 & Cao et al., 2020a,b \\
\hline & LPS-induced podocyte injury & Targets miR-197/MAPK1 & Anti-inflammatory & 2019 & Zhao et al., 2019 \\
\hline Rian/RIAN & UUO mouse, AKI mouse, and pericytes & $\begin{array}{l}\text { Possible interactions with 14q32 } \\
\text { miRNA cluster }\end{array}$ & Anti-fibrotic & 2019 & Bijkerk et al., 2019 \\
\hline Malat1/MALAT1 & AKI; mice; and TECs & $\begin{array}{l}\text { Regulates HIF-1 } \alpha \text { expression through } \\
\text { NF-кB signaling }\end{array}$ & Anti-inflammatory & 2018 & Tian et al., 2018 \\
\hline ZEB1-AS1 & DN mouse and DN patient & $\begin{array}{l}\text { Binds to H3K4 methyltransferase } \\
\text { myeloid and MLL1 to promote ZEB1 } \\
\text { expression } \\
\text { Provides a binding site for p53 }\end{array}$ & Anti-fibrotic & 2018 & Wang et al., 2018a \\
\hline 1700020l14Rik & DN mouse and MCs & $\begin{array}{l}\text { Interacts with miR-34a-5p, } \\
\text { Sirt } 1 / H I F-1 \alpha\end{array}$ & Anti-fibrotic & 2018 & Li et al., 2018 \\
\hline CYP4B1-PS1-001 & DN mouse and MCs & $\begin{array}{l}\text { Regulates Nucleolin to inhibit } \\
\text { proliferation and fibrosis of MCs }\end{array}$ & Anti-fibrotic & $\begin{array}{l}2018 \\
2016\end{array}$ & $\begin{array}{l}\text { Wang et al., 2016a, } \\
2018 c\end{array}$ \\
\hline 3110045C21Rik & UUO mouse and TECs & $\begin{array}{l}\text { Contains binding sites for Pol II and } \\
\text { H3K4m3 }\end{array}$ & Anti-fibrotic & 2016 & Arvaniti et al., 2016 \\
\hline ENSMUST00000147869 & DN mouse and MCs & Possibly targets on Cyp4a12a gene & Anti-fibrotic & 2016 & Wang et al., 2016b \\
\hline
\end{tabular}

Moreover, studies from Yang et al. and Huang et al. have drawn similar conclusions. At the same time, they further demonstrated that lncRNA NEAT1 might promote fibrosis in TECs and MCs by regulating the ERK1/2 or Akt/mTOR signaling pathways (Huang et al., 2019; Yang et al., 2020). It is reported that NEAT1 may also promote renal inflammation in lupus nephritis by upregulating the expression of TRAF6 and activating the NF- $\kappa$ B signaling in lupus nephritis (Zhang et al., 2020b). lncRNA LOC105375913 is upregulated in the TECs of FSGS patients and functions to promote tubulointerstitial fibrosis by regulating $\mathrm{C} 3 \mathrm{a} / \mathrm{p} 38 / \mathrm{XBP}$ signaling pathway and by increasing the expression of Snail and binding to miR-27b (Han et al., 2019). IncRNA LINC00667 is also upregulated in kidney tissues related to the proliferation of TECs. A further mechanistic study has revealed that LINC00667 promotes renal fibrosis by regulating the miR-19b-3p/LINC00667/CTGF signaling pathway (Chen et al., 2019). IncRNA TapSAKI is reported as a biomarker with pro-inflammation and pro-apoptosis in injured TECs and can predict mortality in AKI patients (Lorenzen et al., 2015a).

In diabetic kidney disease, ribonuclease P RNA component H1 (Rpph1) (Zhang et al., 2019b)and Blnc1 are marked as pro-inflammatory lncNRAs (Feng et al., 2019). Moreover, studies on DN have observed the upregulation of lncRNA MALAT1 in TECs and podocytes under high glucose-induced conditions. Induced by TGF- $\beta 1$, MALAT1 facilitates EMT and promotes fibrosis by acting as a sponge for miR-145 or as a feedback regulator of the $\mathrm{Wnt} / \beta$-catenin signaling pathway (Hu et al., 2017; Liu et al., 2019a; Zhang et al., 2019a). However, the pathogenic role of IncRNA MALAT1 in hypoxia-induced
AKI remains unclear. Kölling et al. have identified an increased level of lncRNA MALAT1 in renal biopsies and plasma of AKI patients; in vitro study has also shown a decreased number and proliferation in MALAT1-inhibited ECs. The mechanistic study has discovered that it is transcriptionally activated by hypoxia-inducible factor $1 \alpha$ (HIF-1 $\alpha)$. However, no significant differences in inflammation and fibrosis were shown on MALAT1 knockout and wild-type mice in hypoxia-induced AKI (Kölling et al., 2018).

Also, microarray data have shown a pro-fibrotic role of lncRNA LINC00963 by targeting on FoxO3 gene to regulate the FoxO signaling pathway (Chen et al., 2018). Proinflammatory cytokines, together with NLRP3 inflammasome, may also drive the progression of fibrosis under diabetic conditions. Furthermore, lncRNA Gm4419 is increased in DN and promotes renal fibrosis and inflammation by activating the NF- $\kappa \mathrm{B} / \mathrm{NLRP} 3$ inflammasome signaling pathway in MCs (Yi et al., 2017). However, the functional roles of lncRNA ENSRNOG00000037522 and CHCHD4P4 are remained to be further investigated (Zhang et al., 2017a; Ling et al., 2018).

\section{TRANSFORMING GROWTH FACTOR- $\beta$ /SMAD3-DEPENDENT LNCRNA IN RENAL INFLAMMATION AND FIBROSIS}

Fibrotic responses triggered by TGF- $\beta /$ Smad 3 signaling are of importance in renal fibrogenesis. However, generally blocking the 
TABLE 2 | Pro-fibrotic or pro-inflammatory IncRNAs in renal diseases.

\begin{tabular}{|c|c|c|c|c|c|}
\hline IncRNA & Model & Mechanism/function & Pathological output(s) & Year & References \\
\hline \multirow[t]{2}{*}{ Miat/MIAT } & UUO mouse and TECs & Sponge for miR-145 & Pro-fibrotic & 2020 & Wang et al., 2020b \\
\hline & UUO mouse, IRI mouse, and pericytes & Possible interactions with miR-150 & Pro-fibrotic & 2019 & Bijkerk et al., 2019 \\
\hline \multirow[t]{4}{*}{ Neat1/NEAT1 } & DN mouse and TECs & $\begin{array}{l}\text { Regulates the Klotho/ERK } 1 / 2 \\
\text { signaling }\end{array}$ & Pro-fibrotic & 2020 & Yang et al., 2020 \\
\hline & $\begin{array}{l}\text { Plasma from DN patient, DN mouse, } \\
\text { and MCs }\end{array}$ & Sponge for miR-23c & Pro-fibrotic & 2020 & Li et al., 2020 \\
\hline & DN rat and MCs & Possible regulation of Akt/mTOR & Pro-fibrotic & 2019 & Huang et al., 2019 \\
\hline & MCs & $\begin{array}{l}\text { Targets miR-146b to promote TRAF6 } \\
\text { expression }\end{array}$ & Pro-inflammatory & 2019 & Zhang et al., 2020b \\
\hline LOC105375913 & FSGS patient and TECs & $\begin{array}{l}\text { Regulated by C3a/p38/XBP-1s } \\
\text { signaling and binds to miR-27b }\end{array}$ & Pro-fibrotic & 2019 & Han et al., 2019 \\
\hline LINC00667 & CKD patient, CKD rat, and TECs & $\begin{array}{l}\text { Promotes fibrosis via } \\
\text { miR-19b-3p/LINC00667/CTGF } \\
\text { signaling }\end{array}$ & Pro-fibrotic & 2019 & Chen et al., 2019 \\
\hline TapSAKI & Sepsis-induced AKI; rats; and TECs & $\begin{array}{l}\text { Promotes apoptosis and } \\
\text { inflammation of TECs via } \\
\text { TaqSAKI/miR-22/TLR4/NF-кB } \\
\text { signaling pathway }\end{array}$ & Pro-inflammatory & 2019 & Shen et al., 2019 \\
\hline Rpph1 & $\mathrm{db} / \mathrm{db}$ mice and MCs & $\begin{array}{l}\text { Promotes inflammation and MCs } \\
\text { proliferation through Gal-3/Mek/Erk } \\
\text { signaling }\end{array}$ & Pro-inflammatory & 2019 & Zhang et al., 2019b \\
\hline Blnc1 & DN patient, STZ-induced DN, and TECs & $\begin{array}{l}\text { Interaction with NRF2/HO-1 and } \\
\mathrm{NF}-\kappa \mathrm{B} \text { signaling }\end{array}$ & $\begin{array}{l}\text { Pro-fibrotic; } \\
\text { Pro-inflammatory }\end{array}$ & 2019 & Feng et al., 2019 \\
\hline \multirow[t]{5}{*}{ Malat1/MALAT1 } & DN and TECs & Regulation of Wnt/ $\beta$-catenin signaling & Pro-fibrotic & 2019 & Zhang et al., 2019a \\
\hline & DN mouse and TECs & Sponge for miR-145 & Pro-fibrotic & 2019 & Liu et al., 2019a \\
\hline & $\begin{array}{l}\text { Plasma, renal biopsies from AKI } \\
\text { patients, IRI mouse, TECs, and ECs }\end{array}$ & Regulated by HIF-1 $\alpha$ & No significant effect & 2018 & Kölling et al., 2018 \\
\hline & DN mouse and podocytes & $\begin{array}{l}\text { Binds to SRSF1, interacts with } \\
\beta \text {-catenin }\end{array}$ & Pro-fibrotic & 2017 & Hu et al., 2017 \\
\hline & STZ-induced mice and ECs & $\begin{array}{l}\text { Upregulated IL-6, TNF- } \alpha \text { by activating } \\
\text { SAA3 }\end{array}$ & Pro-inflammatory & 2015 & $\begin{array}{l}\text { Puthanveetil et al., } \\
2015\end{array}$ \\
\hline ENSRNOG00000037522 & DN rat and podocytes & / & Pro-fibrotic & 2018 & Ling et al., 2018 \\
\hline NR_033515 & Serum from DN patient and MCs & Negatively regulates miR-743b-5p & Pro-fibrotic & 2018 & Gao et al., 2018 \\
\hline LINC00963 & 5/6 nephrectomy and rat & Activates the FoxO signaling & Pro-fibrotic & 2018 & Chen et al., 2018 \\
\hline $\mathrm{CHCHD} 4 \mathrm{P} 4$ & Kidney stone, mouse and TECs & / & Pro-fibrotic & 2017 & Zhang et al., 2017a \\
\hline ASncmtRNA-2 & DN mouse and MCs & Upregulated by ROS & Pro-fibrotic & 2017 & Gao et al., 2017 \\
\hline Gm4419 & DN mouse and MCs & $\begin{array}{l}\text { Activates NF-кB/NLRP3-mediated } \\
\text { inflammation and interacts with p50 }\end{array}$ & $\begin{array}{l}\text { Pro-fibrotic; } \\
\text { pro-inflammatory }\end{array}$ & 2017 & Yi et al., 2017 \\
\hline PVT1 & AKI; and LPS-induced TECs & $\begin{array}{l}\text { Binds to TNF- } \alpha \text { and inhibits JNK/ } \\
N F-\kappa B \text { signaling pathway }\end{array}$ & Pro-inflammatory & 2017 & Huang et al., 2017 \\
\hline RP23-45G16.5 & UUO mouse and TECs & $\begin{array}{l}\text { Shows positive correlation with } \\
\text { cdkn1b gene }\end{array}$ & Pro-fibrotic & 2016 & Arvaniti et al., 2016 \\
\hline
\end{tabular}

upstream TGF- $\beta$ signaling may risk promoting inflammation and other side effects. We are beginning to learn that the involvement of TGF- $\beta$ in many other biological processes has been the main obstacle for anti-TGF- $\beta$ therapy. Nevertheless, the majority of studies continue to seek therapeutic targets for anti-fibrotic treatments. miRNA targeting downstream TGF- $\beta$ signaling has been one of the optimal options.

However, the off-target effects and cytotoxicity of miRNA therapies have caught the attention of their specificity and safety. Encouragingly, it has been reported that a group of characterized lncRNAs is involved in TGF- $\beta /$ Smad3-mediated renal fibrosis and inflammation (Zhou et al., 2014, 2015b) (Table 3). These emerging studies should provide possibilities for lncRNA treatment in the future. Ptprd-IR is a novel lncRNA that promotes inflammatory response on TECs in the UUO model. It contains a binding site for Smad3 in its promoter region and is downregulated by deleting Smad3. In contrast, the overexpression of Ptprd-IR enhances inflammatory response by upregulating TGF- $\beta 1-$, interleukin- $1 \beta$ (IL- $1 \beta$ )-induced NF- $\kappa$ Bdriven production of pro-inflammatory cytokines but shows no effect on the TGF- $\beta 1$-induced renal fibrosis ( $\mathrm{Pu}$ et al., 2020). Other novel lncRNA, lncRNA Erbb4-IR, of which expression is induced by TGF- $\beta 1$ via Smad3-dependent mechanism, is significantly increased in the fibrotic UUO model (Feng et al., 2018). Erbb4-IR binds to the inhibitory Smad7 and blocks TGF$\beta /$ Smad3-induced renal fibrosis, while overexpression of Erbb4IR may promote fibrosis by downregulating the expression of Smad7. Of note, Erbb4-IR may also be induced by advanced 
glycosylation end products (AGEs) in DN. It promotes the expression of collagens by binding to miR-29b and hence transcriptionally suppresses miR-29b. Silencing renal Erbb4-IR leads to the upregulation of protective miR-29b and prevents fibrosis (Sun et al., 2018; Xu et al., 2020). Besides, IncRNA ATrich interactive domain 2-IR (Arid2-IR) also contains a Smad3 binding site in the promoter region. Further in vivo study has shown that deletion of Smad3 may abolish upregulation of Arid2-IR in the diseased kidney. Arid2-IR shares a similar mechanism with Ptprd-IR that overexpression of Arid2-IR may promote TGF- $\beta 1-$, IL- $1 \beta$-induced NF- $\kappa$ B-driven inflammation without affecting TGF- $\beta /$ Smad3-mediated renal fibrosis (Zhou et al., 2015a). Nevertheless, the study from Yang et al. (2019) has demonstrated the upregulation and pro-fibrotic effect of Arid2-IR on MCs in DN, that Arid2-IR may be positively regulated by the early growth response protein-1 (Egr1) and promote ECM production.

A novel Smad3-dependent lncRNA, LRNA9884, is induced by AGEs and tightly regulated by $\mathrm{Smad} 3$ in the development and progression of DN. Mechanistically, LRNA9884 directly binds to MCP-1 and enhances the promoter activity of MCP1 at the transcriptional level, thus aggravating the renal injury driven by progressive inflammation (Zhang et al., 2019c). The kidney-enriched TGF- $\beta /$ Smad3-interacting lncRNA, term as IncTSI, is another novel lncRNA that serves as a potential target for renal fibrosis (Wang et al., 2018b). lnc-TSI inhibits renal fibrosis by binding to the $\mathrm{MH} 2$ domain of Smad3, therefore blocking the interaction of Smad3 and T $\beta$ RI and inhibiting the phosphorylation of Smad3. Meanwhile, the overexpression of lnc-TSI prevents the nuclear translocation of Smad2/3/4, resulting in the decreased expression of fibrotic proteins. The anti-fibrotic role of lnc-TSI has further confirmed that the fibrosis index of IgAN patients is negatively correlated with the expression of lnc-TSI.

Collectively, the TGF- $\beta /$ Smad3-mediated lncRNAs may act as anti-fibrotic or pro-fibrotic mediators in the fibrotic process by binding to Smad3, Smad7, or inflammatory molecules to inhibit or enhance renal fibrosis and inflammation. It

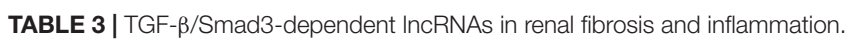

\begin{tabular}{|c|c|c|c|c|c|}
\hline ncRNA & Model & Mechanism/function & Pathological output(s) & Year & References \\
\hline Ptprd-IR (np_4334) & UUO mouse and TECs & $\begin{array}{l}\text { Contains a binding site for Smad3 } \\
\text { and promotes NF-кB-driven } \\
\text { inflammation }\end{array}$ & Pro-inflammatory & 2020 & Pu et al., 2020 \\
\hline \multirow[t]{2}{*}{ Erbb4-IR (np_5318) } & DN mouse, TECs, and MCs & $\begin{array}{l}\text { Binds to miR-29b to downregulate } \\
\text { miR-29b expression }\end{array}$ & Pro-fibrotic & $\begin{array}{l}2020 \\
2018\end{array}$ & $\begin{array}{l}\text { Sun et al., 2018; Xu } \\
\text { et al., } 2020\end{array}$ \\
\hline & UUO mouse and TECs & $\begin{array}{l}\text { Binds to Smad7 to downregulate } \\
\text { Smad7 expression }\end{array}$ & Pro-fibrotic & 2018 & Feng et al., 2018 \\
\hline \multirow[t]{2}{*}{ Arid2-IR (np_28496) } & DN mouse and MCs & $\begin{array}{l}\text { Upregulated by Egr-1-induced ECM } \\
\text { production }\end{array}$ & Pro-fibrotic & 2019 & Yang et al., 2019 \\
\hline & $\begin{array}{l}\text { UUO mouse, anti-GBM mouse, and } \\
\text { TECs }\end{array}$ & $\begin{array}{l}\text { Contains a binding site for Smad3 } \\
\text { and promotes NF-кB-driven } \\
\text { inflammation }\end{array}$ & Pro-inflammatory & 2015 & Zhou et al., 2015a \\
\hline LRNA9884 & DN mouse, TECs, and MCs & $\begin{array}{l}\text { Directly triggers the } \mathrm{MCP}-1 \\
\text { production }\end{array}$ & Pro-inflammatory & 2019 & Zhang et al., 2019c \\
\hline NONHSAG053901 & DN mouse and MCs & Directly binds to Egr-1 & $\begin{array}{l}\text { Pro-fibrotic; } \\
\text { pro-inflammatory }\end{array}$ & 2019 & Peng et al., 2019 \\
\hline HOTAIR & UUO rat and TECs & Regulation of miR-124 /Notch1 & Pro-fibrotic & 2019 & Zhou et al., 2019 \\
\hline IncRNA-ATB & UUO rat and TECs & Regulated by Livin to promote EMT & Pro-fibrotic & 2019 & $\begin{array}{l}\text { Zhou and Jiang, } \\
2019\end{array}$ \\
\hline \multirow[t]{2}{*}{ MEG3 } & TECs & $\begin{array}{l}\text { Regulated by miR-185/DNMT1 axis } \\
\text { to inhibit fibrosis }\end{array}$ & Anti-fibrotic & 2019 & Xue et al., 2019 \\
\hline & TECs; acute renal allograft; and mice & $\begin{array}{l}\text { Function as target of miR- } 181 b-5 p \text { to } \\
\text { regulate the expression of TNF- } \alpha\end{array}$ & Pro-inflammatory & 2019 & Pang et al., 2019 \\
\hline ENST00000453774.1 & $\begin{array}{l}\text { Human renal fibrotic tissue, UUO } \\
\text { mouse, and TECs }\end{array}$ & $\begin{array}{l}\text { Activates autophagy by promoting } \\
\text { ROS defense activates Nrf2/HO-1 } \\
\text { signaling }\end{array}$ & Anti-fibrotic & 2019 & Xiao et al., 2019 \\
\hline Inc-TSI & IgAN patient and UUO mouse & $\begin{array}{l}\text { Binds with Smad3 to block the } \\
\text { interaction between Smad3 and T } \beta R 1\end{array}$ & Anti-fibrotic & 2018 & Wang et al., 2018b \\
\hline \multirow[t]{2}{*}{ TCONS_00088786 } & UUO mouse and TECs & Possible regulation of miR-132 & Pro-fibrotic & 2018 & Zhou et al., 2018 \\
\hline & UUO rat and TECs & / & Pro-fibrotic & 2017 & Sun et al., 2017 \\
\hline TCONS_01496394 & UUO rat and TECs & / & Pro-fibrotic & 2017 & Sun et al., 2017 \\
\hline $\mathrm{H} 19$ & UUO mouse, DN mouse, and TECs & $\begin{array}{l}\text { Stimulated by TGF- } \beta 2 \text { and serves as } \\
\text { a sponge for miR-17 }\end{array}$ & Pro-fibrotic & 2016 & Xie et al., 2016 \\
\hline
\end{tabular}

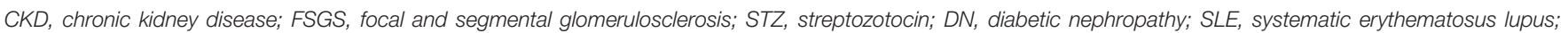

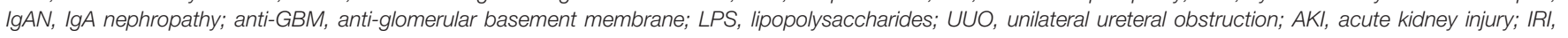
ischemia-reperfusion injury; MCs, mesangial cells; TECs, tubular epithelial cells; ECs, endothelial cells; SAA3, serum amyloid antigen 3. 
has been demonstrated by a large number of studies that lncRNAs act like an endogenous RNA to compete for miRNA to regulate the target transcripts at the transcriptional or post-transcriptional level during renal fibrosis. In the early stage of DN, the expression of lncRNA NONHSAG053901 is highly increased in DN mice and MCs. The functional study has revealed that the overexpression of NONHSAG053901 promotes fibrosis, inflammation, and proliferation in MCs. Mechanistically, NONHSAG053901 directly binds to Egr-1, which later interacts with TGF- $\beta$ to upregulate the release of proinflammatory cytokines to promote Egr-1/ TGF- $\beta$ mediated renal inflammation (Peng et al., 2019). In addition, the pro-fibrotic lncRNA HOTAIR is significantly upregulated in TGF- $\beta 1$-induced TECs and UUO rat kidney. Depletion on HOTAIR upregulates miR-124 to block the Notch1 signal pathway, therefore improving the EMT and reducing the accumulation of fibrotic proteins such as fibronectin and $\alpha$-SMA (Zhou et al., 2019).

lnc-ATB has also been proven to be the critical regulator stimulated by TGF- $\beta$ that mediates the EMT process. The expression of IncRNA-ATB is significantly increased in TECs and the UUO kidney under TGF- $\beta$ and Livin regulation (Zhou and Jiang, 2019). Another lncRNA regulated by TGF- $\beta$ is maternally expressed gene 3 (MEG3), inhibited in TGF- $\beta$-stimulated TECs. DNA methyltransferases 1 (DNMT1), regulated by miR185, can positively modulate the methylation state of $\mathrm{CpG}$ islands in the promoter region of MEG3. Overexpression of lncRNA MEG3 reverses TGF- $\beta$-induced fibrosis in TECs. Thus, lncRNA MEG3 exerts an anti-fibrotic effect in TGF$\beta$-promoted EMT and is regulated by the miR-185/DNMT1 signaling pathway (Xue et al., 2019). However, one study had investigated the pro-inflammatory effect of MEG3 in the acute renal allograft model (Pang et al., 2019). The antifibrotic lncRNA, ENST00000453774.1, is also downregulated in TGF- $\beta$-induced TECs and UUO model, especially in the fibrotic renal biopsies from patients. ENST00000453774.1 may regulate the Nrf2-keap1/Nrf2 nuclei translocation/HO-1 and NQO-1 signaling to activate the pro-survival autophagy of TECs, therefore promoting ROS defense and reducing the production of ECM markers such as fibronectin and collagen I (Xiao et al., 2019).

Nevertheless, the mechanism of some pro-fibrotic lncRNAs is still obscure. Based on the transcriptome sequencing study, a group of IncRNAs that contain Smad3 binding motifs in the promoter region has been identified. Among these lncRNAs, TCONS_00088786 and TCONS_01496394 are confirmed to be regulated by TGF- $\beta$ in a time and dose-dependent manner. Knockdown of TCONS_00088786 may inhibit the mRNA expression profile of the gene Acta1, Colla1, and Col3a1, while knockdown of TCONS_01496394 decreases the mRNA expression of Ctgf and Fn1, suggesting their potential in promoting renal fibrosis (Sun et al., 2017). Although a functional study has shown a positive regulation of TCONS_00088786 on miR-132, the underlying mechanism is unclear (Zhou et al., 2018). Interestingly, the expression of lncRNA H19 is also increased in TECs and the UUO model. IncRNA H19 is activated in embryonic cells, but its expression is significantly decreased after birth. Under the renal fibrotic condition, H19 is upregulated by TGF- $\beta 2$ to promote the production of ECM-related proteins. Knockdown of $\mathrm{H} 19$ restores the renal functions and inhibits TGF- $\beta 2$-induced fibrosis. It is demonstrated that H19 serves as a sponge for miR-17 and negatively regulates $\mathrm{miR}-17$ in the process of fibrogenesis (Xie et al., 2016). However, further evidence on how H19 and miR-17 contribute to the network of renal fibrosis remains unclear.

\section{FUTURE PERSPECTIVES: LNCRNA AS A NOVEL THERAPEUTIC TARGET FOR KIDNEY DISEASE}

The activation of TGF- $\beta$ /Smad signaling is one of the most characterized features in fibrosis. Although TGF- $\beta$ is the crucial driver of fibrotic response, it also acts as an anti-inflammatory cytokine and essential mediator that regulates a wide range of biological processes in different cell types and disease conditions. Numerous studies reveal that lncRNAs participate in the emergence and progression of kidney diseases. An outline is becoming manifest in the contribution of TGF- $\beta /$ Smad-mediated lncRNAs in renal fibrogenesis.

We are now getting better closer to understand how these lncRNAs regulate fibrosis. They can bind to the Smads proteins to exert either anti- or pro-fibrotic effects. They can also serve as miRNA sponges and interact with other signaling pathways to regulate ECM accumulation, EMT, MMT, or other fibrotic processes.

Based on the cell type-, tissue- and disease stage-dependent specialties, lncRNA may also present as biomarkers for clinical diagnosis in renal diseases (Brandenburger et al., 2018; Cheng et al., 2019; Li et al., 2019; Liu et al., 2019b; Loganathan et al., 2020). Interestingly, lncRNAs are relevant biomarkers for disease due to their existence with proteins or in vesicles in the extracellular space under pathological conditions (Teng and Ghoshal, 2015; Ellinger et al., 2016; Zhang et al., 2017c; E, S., Costa et al., 2018; Sarfi et al., 2019). Studies have demonstrated that circulating lncRNAs in body fluid, lncRNA GAS8-AS1, H19, metastasis-associated lung adenocarcinoma transcript 1 (MALAT1), and HOTAIR may be used as promising biomarkers to predict the early progression of cancers (Zhang et al., 2016, 2017b; Du et al., 2018a). Notably, the lncRNA expression profiles in urine also contribute to the early detection of acute T cellmediated rejection of renal allografts (Lorenzen et al., 2015b), highlighting the importance of lncRNAs in $\mathrm{T}$ cell-mediated immune response during renal injuries (Hu et al., 2013).

The modulation of lncRNAs on renal fibrosis is a promising therapeutic target for fibrosis. However, it remains largely unexplored. The low expression amounts, the less conservation between species, the functional complexity, and the difficulty in modifying structures and locations of lncRNA in nuclear or cytoplasmic compartments have halted the development of lncRNA therapies.

Nevertheless, new technologies such as CRISPR/Cas9 editing (Wang et al., 2019; Horlbeck et al., 2020), Gapmer antisense 
oligonucleotide-mediated lncRNA silencing (Castanotto et al., 2015; Kuespert et al., 2020), plasmid/vector-delivery short hairpin RNAs (shRNAs) (Zhu et al., 2019; Yao et al., 2020) and ultrasound-mediated gene transfer method (Zhou et al., 2015a; Feng et al., 2018; Sun et al., 2018; Zhang et al., 2019c) may represent the novel strategies to modulate the expression and function of lncRNA in kidney diseases in the future.

\section{AUTHOR CONTRIBUTIONS}

Y-YG, J-YD, and X-RH wrote the manuscript, X-SL and H-YL revised and edited the manuscript. All authors contributed to the discussion of this manuscript.

\section{REFERENCES}

Arvaniti, E., Moulos, P., Vakrakou, A., Chatziantoniou, C., Chadjichristos, C., Kavvadas, P., et al. (2016). Whole-transcriptome analysis of UUO mouse model of renal fibrosis reveals new molecular players in kidney diseases. Sci. Rep. 6:26235.

Batista, P. J., and Chang, H. Y. (2013). Long noncoding RNAs: cellular address codes in development and disease. Cell 152, 1298-1307. doi: 10.1016/j.cell.2013. 02.012

Bijkerk, R., Au, Y. W., Stam, W., Duijs, J., Koudijs, A., Lievers, E., et al. (2019). Long Non-coding RNAs rian and miat mediate myofibroblast formation in kidney fibrosis. Front. Pharmacol. 10:215. doi: 10.3389/fphar.2019.00215

Bonafoux, D., and Lee, W.-C. (2009). Strategies for TGF-beta modulation: a review of recent patents. Expert Opin. Ther. Patents 19, 1759-1769. doi: 10.1517/ 13543770903397400

Border, W. A., Okuda, S., Languino, L. R., Sporn, M. B., and Ruoslahti, E. (1990). Suppression of experimental glomerulonephritis by antiserum against transforming growth factor beta 1 . Nature 346, 371-374. doi: 10.1038/346371a0

Brandenburger, T., Salgado Somoza, A., Devaux, Y., and Lorenzen, J. M. (2018). Noncoding RNAs in acute kidney injury. Kidney Int. 94, 870-881. doi: 10.1016/ j.kint.2018.06.033

Brockdorff, N., Ashworth, A., Kay, G. F., Cooper, P., Smith, S., Mccabe, V. M., et al. (1991). Conservation of position and exclusive expression of mouse Xist from the inactive X chromosome. Nature 351, 329-331. doi: 10.1038/351329a0

Brown, C. J., Ballabio, A., Rupert, J. L., Lafreniere, R. G., Grompe, M., Tonlorenzi, R., et al. (1991). A gene from the region of the human X inactivation centre is expressed exclusively from the inactive X chromosome. Nature 349, 38-44. doi: 10.1038/349038a0

Cao, H. Y., Li, D., Wang, Y. P., Lu, H. X., Sun, J., and Li, H. B. (2020a). Clinical significance of reduced expression of lncRNA TUG1 in the peripheral blood of systemic lupus erythematosus patients. Int. J. Rheum. Dis. 23, 428-434. doi: 10.1111/1756-185x.13786

Cao, H. Y., Li, D., Wang, Y. P., Lu, H. X., Sun, J., and Li, H. B. (2020b). The protection of NF- $\mathrm{B}$ inhibition on kidney injury of systemic lupus erythematosus mice may be correlated with lncRNA TUG1. Kaohsiung J. Med. Sci. 36, 354-362. doi: 10.1002/kjm2.12183

Castanotto, D., Lin, M., Kowolik, C., Wang, L., Ren, X.-Q., Soifer, H. S., et al. (2015). A cytoplasmic pathway for gapmer antisense oligonucleotide-mediated gene silencing in mammalian cells. Nucleic Acids Res. 43, 9350-9361. doi: 10.1093/nar/gkv964

Che, H., Wang, Y., Li, H., Li, Y., Sahil, A., Lv, J., et al. (2020). Melatonin alleviates cardiac fibrosis via inhibiting lncRNA MALAT1/miR-141-mediated NLRP3 inflammasome and TGF- $\beta 1 /$ Smads signaling in diabetic cardiomyopathy. Faseb J. 34, 5282-5298. doi: 10.1096/fj.201902692r

Chen, H. Y., Huang, X. R., Wang, W., Li, J. H., Heuchel, R. L., Chung, A. C., et al. (2011). The protective role of Smad7 in diabetic kidney disease: mechanism and therapeutic potential. Diabetes 60, 590-601. doi: 10.2337/db10-0403

\section{FUNDING}

This work was supported by The National Natural Science Foundation of China (Grant Nos. 81903956 and 81873261), The Guangdong-Hong Kong-Macao-Joint Labs Program from Guangdong Science and Technology (2019B121205005), The Research Grants Council of Hong Kong (Grants GRF 14163317, 14117418, 14104019, R4012-18, and C7018-16G), Lui Che Woo Institute of Innovative Medicine (CARE), The Health and Medical Research Fund of Hong Kong (Grants HMRF 05161326, 06173986, and 07180516), The Project of Guangdong Province Administration of Traditional Chinese Medicine (Grant No. 20201133). The Basic and Applied Basic Research Project of Guangzhou Science and Technology Department (202102020011).

Chen, W., Zhang, L., Zhou, Z.-Q., Ren, Y.-Q., Sun, L.-N., Man, Y.-L., et al. (2018). Effects of Long Non-Coding RNA LINC00963 on renal interstitial fibrosis and oxidative stress of rats with chronic renal failure via the foxo signaling pathway. Cell. Physiol. Biochem. Int. J. Exp. Cell. Physiol. Biochem. Pharmacol. 46, 815-828. doi: 10.1159/000488739

Chen, W., Zhou, Z.-Q., Ren, Y.-Q., Zhang, L., Sun, L.-N., Man, Y.-L., et al. (2019). Effects of long non-coding RNA LINC00667 on renal tubular epithelial cell proliferation, apoptosis and renal fibrosis via the miR-19b3p/LINC00667/CTGF signaling pathway in chronic renal failure. Cell. Signal. 54, 102-114. doi: 10.1016/j.cellsig.2018.10.016

Chen, Y. C., Kuo, P. Y., Chou, Y. C., Chong, H. E., Hsieh, Y. T., Yang, M. L. et al. (2020). Up-regulated expression of pro-apoptotic long noncoding RNA lincRNA-p21 with enhanced cell apoptosis in lupus nephritis. Int. J. Mol. Sci. 22:301. doi: 10.3390/ijms22010301

Cheng, G., Liu, D., Liang, H., Yang, H., Chen, K., and Zhang, X. (2019). A cluster of long non-coding RNAs exhibit diagnostic and prognostic values in renal cell carcinoma. Aging (Albany NY) 11, 9597-9615. doi: 10.18632/aging. 102407 doi: 10.18632/aging.102407

Cho, M. E., Smith, D. C., Branton, M. H., Penzak, S. R., and Kopp, J. B. (2007). Pirfenidone slows renal function decline in patients with focal segmental glomerulosclerosis. Clin. J. Am. Soc. Nephrol. 2, 906-913. doi: 10.2215/cjn. 01050207

Chung, A. C., Huang, X. R., Zhou, L., Heuchel, R., Lai, K. N., and Lan, H. Y. (2009). Disruption of the Smad7 gene promotes renal fibrosis and inflammation in unilateral ureteral obstruction (UUO) in mice. Nephrol. Dial. Transplant 24, 1443-1454. doi: 10.1093/ndt/gfn699

Chung, A. C., and Lan, H. Y. (2011). Chemokines in renal injury. J. Am. Soc. Nephrol. 22, 802-809. doi: 10.1681/asn.2010050510

Chung, A. C., Zhang, H., Kong, Y. Z., Tan, J. J., Huang, X. R., Kopp, J. B., et al. (2010). Advanced glycation end-products induce tubular CTGF via TGF-betaindependent Smad3 signaling. J. Am. Soc. Nephrol. 21, 249-260. doi: 10.1681/ asn. 2009010018

Dai, X. Y., Zhou, L., Huang, X. R., Fu, P., and Lan, H. Y. (2015). Smad7 protects against chronic aristolochic acid nephropathy in mice. Oncotarget 6, 11930 11944. doi: 10.18632 /oncotarget. 3718

Derynck, R., and Zhang, Y. E. (2003). Smad-dependent and Smad-independent pathways in TGF-beta family signalling. Nature 425, 577-584. doi: 10.1038/ nature 02006

Du, L., Duan, W., Jiang, X., Zhao, L., Li, J., Wang, R., et al. (2018a). Cell-free lncRNA expression signatures in urine serve as novel non-invasive biomarkers for diagnosis and recurrence prediction of bladder cancer. J. Cell. Mol. Med. 22, 2838-2845. doi: $10.1111 / \mathrm{jcmm} .13578$

Du, N., Xu, Z., Gao, M., Liu, P., Sun, B., and Cao, X. (2018b). Combination of Ginsenoside Rg1 and Astragaloside IV reduces oxidative stress and inhibits TGF-betal/Smads signaling cascade on renal fibrosis in rats with diabetic nephropathy. Drug Des. Devel. Ther. 12, 3517-3524. doi: 10.2147/dddt. 171286 doi: $10.2147 /$ dddt.s171286 
E, S., Costa, M. C., Kurc, S., Drożdż, A., Cortez-Dias, N., and Enguita, F. J. (2018). The circulating non-coding RNA landscape for biomarker research: lessons and prospects from cardiovascular diseases. Acta Pharmacol. Sin. 39, 1085-1099. doi: 10.1038/aps.2018.35

Ellinger, J., Gevensleben, H., Müller, S. C., and Dietrich, D. (2016). The emerging role of non-coding circulating RNA as a biomarker in renal cell carcinoma. Expert Rev. Mol. Diagn. 16, 1059-1065. doi: 10.1080/14737159.2016.1239531

Fan, J. M., Ng, Y. Y., Hill, P. A., Nikolic-Paterson, D. J., Mu, W., Atkins, R. C., et al. (1999). Transforming growth factor-beta regulates tubular epithelialmyofibroblast transdifferentiation in vitro. Kidney Int. 56, 1455-1467. doi: 10.1046/j.1523-1755.1999.00656.x

Feng, M., Tang, P. M., Huang, X. R., Sun, S. F., You, Y. K., Xiao, J., et al. (2018). TGF-beta mediates renal fibrosis via the Smad3-Erbb4-IR long noncoding RNA axis. Mol. Ther. 26, 148-161. doi: 10.1016/j.ymthe.2017.09.024

Feng, X., Zhao, J., Ding, J., Shen, X., Zhou, J., and Xu, Z. (2019). LncRNA Blnc1 expression and its effect on renal fibrosis in diabetic nephropathy. Am. J. Trans. Res. 11, 5664-5672.

Flynn, R. A., and Chang, H. Y. (2014). Long noncoding RNAs in cell-fate programming and reprogramming. Cell Stem Cell 14, 752-761. doi: 10.1016/ j.stem.2014.05.014

Gao, J., Wang, W., Wang, F., and Guo, C. (2018). LncRNA-NR_033515 promotes proliferation, fibrogenesis and epithelial-to-mesenchymal transition by targeting miR-743b-5p in diabetic nephropathy. Biomed. Pharmacother. 106, 543-552. doi: 10.1016/j.biopha.2018.06.104

Gao, Y., Chen, Z.-Y., Wang, Y., Liu, Y., Ma, J.-X., and Li, Y.-K. (2017). Long non-coding RNA ASncmtRNA-2 is upregulated in diabetic kidneys and high glucose-treated mesangial cells. Exp. Ther. Med. 13, 581-587. doi: 10.3892/etm. 2017.4027

Glassock, R. J., Warnock, D. G., and Delanaye, P. (2017). The global burden of chronic kidney disease: estimates, variability and pitfalls. Nat. Rev. Nephrol. 13, 104-114. doi: 10.1038/nrneph.2016.163

Gu, Y.-Y., Liu, X.-S., Huang, X.-R., Yu, X.-Q., and Lan, H.-Y. (2020a). Diverse role of TGF- $\beta$ in kidney disease. Front. Cell Dev. Biol. 8:123. doi: 10.3389/fcell.2020. 00123

Gu, Y.-Y., Liu, X.-S., Huang, X.-R., Yu, X.-Q., and Lan, H.-Y. (2020b). TGF- $\beta$ in renal fibrosis: triumphs and challenges. Future Med. Chem. 12, 853-866. doi: 10.4155/fmc-2020-0005

Gu, Y. Y., Lu, F. H., Huang, X. R., Zhang, L., Mao, W., Yu, X. Q., et al. (2020c). Non-Coding RNAs as biomarkers and therapeutic targets for diabetic kidney disease. Front. Pharmacol. 11:583528. doi: 10.3389/fphar.2020.583528

Györfi, A. H., Matei, A.-E., and Distler, J. H. W. (2018). Targeting TGF- $\beta$ signaling for the treatment of fibrosis. Matrix Biol. J. Int. Soc. Matrix Biol. 6, 8-27. doi: 10.1016/j.matbio.2017.12.016

Han, R., Hu, S., Qin, W., Shi, J., Zeng, C., Bao, H., et al. (2019). Upregulated long noncoding RNA LOC105375913 induces tubulointerstitial fibrosis in focal segmental glomerulosclerosis. Sci. Rep. 9:716.

Hangauer, M. J., Vaughn, I. W., and Mcmanus, M. T. (2013). Pervasive transcription of the human genome produces thousands of previously unidentified long intergenic noncoding RNAs. PLoS Genet. 9:e1003569. doi: 10.1371/journal.pgen.1003569

Horlbeck, M. A., Liu, S. J., Chang, H. Y., Lim, D. A., and Weissman, J. S. (2020). Fitness effects of CRISPR/Cas9-targeting of long noncoding RNA genes. Nat. Biotechnol. 38, 573-576. doi: 10.1038/s41587-020-0428-0

Hou, C. C., Wang, W., Huang, X. R., Fu, P., Chen, T. H., Sheikh-Hamad, D., et al. (2005). Ultrasound-microbubble-mediated gene transfer of inducible Smad7 blocks transforming growth factor-beta signaling and fibrosis in rat remnant kidney. Am. J. Pathol. 166, 761-771. doi: 10.1016/s0002-9440(10)62297-3

Hu, G., Tang, Q., Sharma, S., Yu, F., Escobar, T. M., Muljo, S. A., et al. (2013). Expression and regulation of intergenic long noncoding RNAs during $\mathrm{T}$ cell development and differentiation. Nat. Immunol. 14, 1190-1198. doi: 10.1038/ ni. 2712

Hu, M., Wang, R., Li, X., Fan, M., Lin, J., Zhen, J., et al. (2017). LncRNA MALAT1 is dysregulated in diabetic nephropathy and involved in high glucoseinduced podocyte injury via its interplay with $\beta$-catenin. J. Cell. Mol. Med. 21, 2732-2747. doi: 10.1111/jcmm.13189

Hu, S. Y., Jia, X. Y., Li, J. N., Zheng, X., Ao, J., Liu, G., et al. (2016). T cell infiltration is associated with kidney injury in patients with anti-glomerular basement membrane disease. Sci. China Life Sci. 59, 1282-1289. doi: 10.1007/ s11427-016-5030-9

Huang, S., Xu, Y., Ge, X., Xu, B., Peng, W., Jiang, X., et al. (2019). Long noncoding RNA NEAT1 accelerates the proliferation and fibrosis in diabetic nephropathy through activating Akt/mTOR signaling pathway. J. Cell. Physiol. 234, 1120011207. doi: $10.1002 /$ jcp. 27770

Huang, W., Lan, X., Li, X., Wang, D., Sun, Y., Wang, Q., et al. (2017). Long non-coding RNA PVT1 promote LPS-induced septic acute kidney injury by regulating $\mathrm{TNF} \alpha$ and $\mathrm{JNK} / \mathrm{NF}-\kappa \mathrm{B}$ pathways in $\mathrm{HK}-2$ cells. Int. Immunopharmacol. 47, 134-140. doi: 10.1016/j.intimp.2017.03.030

Huang, X. R., Chung, A. C., Wang, X. J., Lai, K. N., and Lan, H. Y. (2008a). Mice overexpressing latent TGF-betal are protected against renal fibrosis in obstructive kidney disease. Am. J. Physiol. Renal. Physiol. 295, F118-F127.

Huang, X. R., Chung, A. C., Zhou, L., Wang, X. J., and Lan, H. Y. (2008b). Latent TGF-betal protects against crescentic glomerulonephritis. J. Am. Soc. Nephrol. 19, 233-242. doi: 10.1681/asn.2007040484

Isaka, Y. (2018). Targeting TGF-beta signaling in kidney fibrosis. Int. J. Mol. Sci. 19:2532. doi: 10.3390/ijms19092532

Iwano, M., Plieth, D., Danoff, T. M., Xue, C., Okada, H., and Neilson, E. G. (2002). Evidence that fibroblasts derive from epithelium during tissue fibrosis. J. Clin. Invest. 110, 341-350. doi: 10.1172/jci0215518

Jiang, H., Wu, F., Jiang, N., Gao, J., and Zhang, J. (2019). Reconstruction and analysis of competitive endogenous RNA network reveals regulatory role of long non-coding RNAs in hepatic fibrosis. Mol. Med. Rep. 20, 4091-4100.

Jiang, X., and Zhang, F. (2017). Long noncoding RNA: a new contributor and potential therapeutic target in fibrosis. Epigenomics 9, 1233-1241. doi: 10.2217/ epi-2017-0020

Ju, W., Ogawa, A., Heyer, J., Nierhof, D., Yu, L., Kucherlapati, R., et al. (2006). Deletion of Smad2 in mouse liver reveals novel functions in hepatocyte growth and differentiation. Mol. Cell Biol. 26, 654-667. doi: 10.1128/mcb.26.2.654-667. 2006

Ka, S. M., Huang, X. R., Lan, H. Y., Tsai, P. Y., Yang, S. M., Shui, H. A., et al. (2007). Smad7 gene therapy ameliorates an autoimmune crescentic glomerulonephritis in mice. J. Am. Soc. Nephrol. 18, 1777-1788. doi: 10.1681/asn.2006080901

Kinsey, G. R., and Okusa, M. D. (2014). Expanding role of T cells in acute kidney injury. Curr. Opin. Nephrol. Hypertens 23, 9-16. doi: 10.1097/01.mnh. 0000436695.29173.de

Kölling, M., Genschel, C., Kaucsar, T., Hübner, A., Rong, S., Schmitt, R., et al. (2018). Hypoxia-induced long non-coding RNA Malat1 is dispensable for renal ischemia/reperfusion-injury. Sci. Rep. 8:3438.

Kopp, J. B., Factor, V. M., Mozes, M., Nagy, P., Sanderson, N., Bottinger, E. P., et al. (1996). Transgenic mice with increased plasma levels of TGF-beta 1 develop progressive renal disease. Lab. Invest 74, 991-1003.

Kuespert, S., Heydn, R., Peters, S., Wirkert, E., Meyer, A.-L., Siebörger, M., et al. (2020). Antisense oligonucleotide in LNA-gapmer design targeting TGFBR2-a key single gene target for safe and effective inhibition of TGF $\beta$ signaling. Int. J. Mol. Sci. 21:1952. doi: 10.3390/ijms21061952

Lan, H. Y. (2008). Smad7 as a therapeutic agent for chronic kidney diseases. Front. Biosci. 13:4984-4992. doi: 10.2741/3057

Lan, H. Y. (2011). Diverse roles of TGF-beta/Smads in renal fibrosis and inflammation. Int. J. Biol. Sci. 7, 1056-1067. doi: 10.7150/ijbs.7.1056

Lan, H. Y. (2012a). Smads as therapeutic targets for chronic kidney disease. Kidney Res. Clin. Pract. 31, 4-11. doi: 10.1016/j.krcp.2011.12.001

Lan, H. Y. (2012b). Transforming growth factor-beta/Smad signalling in diabetic nephropathy. Clin. Exp. Pharmacol. Physiol. 39, 731-738. doi: 10.1111/j.14401681.2011.05663.x

Lan, H. Y., and Chung, A. C. (2012). TGF-beta/Smad signaling in kidney disease. Semin. Nephrol. 32, 236-243. doi: 10.1016/j.semnephrol.2012.04.002

Lan, H. Y., Mu, W., Tomita, N., Huang, X. R., Li, J. H., Zhu, H. J., et al. (2003). Inhibition of renal fibrosis by gene transfer of inducible Smad7 using ultrasound-microbubble system in rat UUO model. J. Am. Soc. Nephrol. 14, 1535-1548. doi: 10.1097/01.asn.0000067632.04658.b8

Li, A., Peng, R., Sun, Y., Liu, H., Peng, H., and Zhang, Z. (2018). LincRNA 1700020I14Rik alleviates cell proliferation and fibrosis in diabetic nephropathy via miR-34a-5p/Sirt1/HIF-1 $\alpha$ signaling. Cell Death Dis. 9:461.

Li, J., Qu, X., Yao, J., Caruana, G., Ricardo, S. D., Yamamoto, Y., et al. (2010). Blockade of endothelial-mesenchymal transition by a Smad3 inhibitor 
delays the early development of streptozotocin-induced diabetic nephropathy. Diabetes 59, 2612-2624. doi: 10.2337/db09-1631

Li, J. H., Zhu, H. J., Huang, X. R., Lai, K. N., Johnson, R. J., and Lan, H. Y. (2002). Smad7 inhibits fibrotic effect of TGF-Beta on renal tubular epithelial cells by blocking Smad2 activation. J. Am. Soc. Nephrol. 13, 1464-1472. doi: 10.1097/01.asn.0000014252.37680.e4

Li, M. O., and Flavell, R. A. (2008). TGF-beta: a master of all T cell trades. Cell 134, 392-404. doi: 10.1016/j.cell.2008.07.025

Li, N., Cui, Y., Yin, M., and Liu, F. (2019). Screening potential prognostic biomarkers of long non-coding RNAs for predicting the risk of chronic kidney disease. Braz. J. Med. Biol. Res. 52:e8333.

Li, N., Jia, T., and Li, Y. R. (2020). LncRNA NEAT1 accelerates the occurrence and development of diabetic nephropathy by sponging miR-23c. Eur. Rev. Med. Pharmacol. Sci. 24, 1325-1337.

Liao, Z., Ye, Z., Xue, Z., Wu, L., Ouyang, Y., Yao, C., et al. (2019). Identification of renal long non-coding RNA RP11-2B6.2 as a positive regulator of type I interferon signaling pathway in lupus nephritis. Front. Immunol. 10:975. doi: 10.3389/fimmu.2019.00975

Ling, L., Tan, Z., Zhang, C., Gui, S., Hu, Y., and Chen, L. (2018). Long noncoding RNA ENSRNOG00000037522 is involved in the podocyte epithelial-mesenchymal transition in diabetic rats. Int. J. Mol. Med. 41, 27042714.

Liu, B., Qiang, L., Wang, G. D., Duan, Q., and Liu, J. (2019a). LncRNA MALAT1 facilities high glucose induced endothelial to mesenchymal transition and fibrosis via targeting miR-145/ZEB2 axis. Eur. Rev. Med. Pharmacol. Sci. 23, 3478-3486.

Liu, G. X., Li, Y. Q., Huang, X. R., Wei, L., Chen, H. Y., Shi, Y. J., et al. (2013). Disruption of Smad7 promotes ANG II-mediated renal inflammation and fibrosis via Sp1-TGF-beta/Smad3-NF.kappaB-dependent mechanisms in mice. PLoS One 8:e53573. doi: 10.1371/journal.pone.0053573

Liu, G. X., Li, Y. Q., Huang, X. R., Wei, L. H., Zhang, Y., Feng, M., et al. (2014). Smad7 inhibits AngII-mediated hypertensive nephropathy in a mouse model of hypertension. Clin. Sci. (Lond) 127, 195-208. doi: 10.1042/cs20130706

Liu, Y. (2011). Cellular and molecular mechanisms of renal fibrosis. Nat. Rev. Nephrol. 7:684. doi: 10.1038/nrneph.2011.149

Liu, Z., Huang, X. R., and Lan, H. Y. (2012). Smad3 mediates ANG II-induced hypertensive kidney disease in mice. Am. J. Physiol. Renal. Physiol. 302, F986F997.

Liu, Z., Wang, Y., Shu, S., Cai, J., Tang, C., and Dong, Z. (2019b). Non-coding RNAs in kidney injury and repair. Am. J. Physiol. Cell Physiol. 317, C177-C188.

Lodyga, M., and Hinz, B. (2019). TGF- $\beta 1$ - A truly transforming growth factor in fibrosis and immunity. Semin. Cell Dev. Biol. 101, 123-139. doi: 10.1016/j. semcdb.2019.12.010

Loeffler, I., Liebisch, M., Allert, S., Kunisch, E., Kinne, R. W., and Wolf, G. (2018). FSP1-specific SMAD2 knockout in renal tubular, endothelial, and interstitial cells reduces fibrosis and epithelial-to-mesenchymal transition in murine STZinduced diabetic nephropathy. Cell Tissue Res. 372, 115-133. doi: 10.1007/ s00441-017-2754-1

Loganathan, T. S., Sulaiman, S. A., Abdul Murad, N. A., Shah, S. A., Abdul Gafor, A. H., Jamal, R., et al. (2020). Interactions among non-coding RNAs in diabetic nephropathy. Front. Pharmacol. 11:191. doi: 10.3389/fphar.2020. 00191

Lopez-Hernandez, F. J., and Lopez-Novoa, J. M. (2012). Role of TGF-beta in chronic kidney disease: an integration of tubular, glomerular and vascular effects. Cell Tissue Res. 347, 141-154. doi: 10.1007/s00441-011-1275-6

Lorenzen, J. M., Schauerte, C., Kielstein, J. T., Hübner, A., Martino, F., Fiedler, J., et al. (2015a). Circulating long noncoding RNATapSaki is a predictor of mortality in critically ill patients with acute kidney injury. Clin. Chem. 61, 191-201. doi: 10.1373/clinchem.2014.230359

Lorenzen, J. M., Schauerte, C., Kölling, M., Hübner, A., Knapp, M., Haller, H., et al. (2015b). Long noncoding RNAs in urine are detectable and may enable early detection of acute $\mathrm{t}$ cell-mediated rejection of renal allografts. Clin. Chem. 61, 1505-1514. doi: 10.1373/clinchem.2015.243600

Lu, S., Dong, L., Jing, X., Gen-Yang, C., Zhang-Suo, L., and Zhan-Zheng, Z. (2020). Abnormal lncRNA CCAT1/microRNA-155/SIRT1 axis promoted inflammatory response and apoptosis of tubular epithelial cells in LPS caused acute kidney injury. Mitochondrion 53, 76-90. doi: 10.1016/j.mito.2020. 03.010 doi: $10.1016 /$ j.mito.2020.03.010
Ludwig-Portugall, I., and Kurts, C. (2014). T cell isolation from mouse kidneys. Methods Mol. Biol. 1193, 27-35. doi: 10.1007/978-1-4939-1212-4_4

Mack, M., and Yanagita, M. (2015). Origin of myofibroblasts and cellular events triggering fibrosis. Kidney Int. 87, 297-307. doi: 10.1038/ki.2014.287

Majo, J., Klinkhammer, B. M., Boor, P., and Tiniakos, D. (2019). Pathology and natural history of organ fibrosis. Curr. Opin. Pharmacol. 49, 82-89. doi: 10. 1016/j.coph.2019.09.009

March, J. T., Golshirazi, G., Cernisova, V., Carr, H., Leong, Y., Lu-Nguyen, N., et al. (2018). Targeting TGF $\beta$ signaling to address fibrosis using antisense oligonucleotides. Biomedicines 6:74. doi: 10.3390/biomedicines6030074

Meng, X. M. (2019). Inflammatory mediators and renal fibrosis. Adv. Exp. Med. Biol. 1165, 381-406. doi: 10.1007/978-981-13-8871-2_18

Meng, X. M., Huang, X. R., Xiao, J., Chung, A. C., Qin, W., Chen, H. Y., et al. (2012). Disruption of Smad4 impairs TGF-beta/Smad3 and Smad7 transcriptional regulation during renal inflammation and fibrosis in vivo and in vitro. Kidney Int. 81, 266-279. doi: 10.1038/ki.2011.327

Meng, X. M., Nikolic-Paterson, D. J., and Lan, H. Y. (2014). Inflammatory processes in renal fibrosis. Nat. Rev. Nephrol. 10, 493-503. doi: 10.1038/nrneph. 2014.114

Meng, X. M., Nikolic-Paterson, D. J., and Lan, H. Y. (2016a). TGF-beta: the master regulator of fibrosis. Nat. Rev. Nephrol. 12, 325-338. doi: 10.1038/nrneph. 2016.48 doi: $10.1038 /$ nrneph.2016.48

Meng, X. M., Wang, S., Huang, X. R., Yang, C., Xiao, J., Zhang, Y., et al. (2016b). Inflammatory macrophages can transdifferentiate into myofibroblasts during renal fibrosis. Cell Death Dis. 7:e2495. doi: 10.1038/cddis.2016.402

Meng, X. M., Zhang, Y., Huang, X. R., Ren, G. L., Li, J., and Lan, H. Y. (2015). Treatment of renal fibrosis by rebalancing TGF-beta/Smad signaling with the combination of asiatic acid and naringenin. Oncotarget 6, 36984-36997. doi: 10.18632/oncotarget.6100

Morishita, Y., Yoshizawa, H., Watanabe, M., Ishibashi, K., Muto, S., Kusano, E., et al. (2014). siRNAs targeted to Smad4 prevent renal fibrosis in vivo. Sci. Rep. 4:6424.

Ng, Y. Y., Hou, C. C., Wang, W., Huang, X. R., and Lan, H. Y. (2005). Blockade of NFkappaB activation and renal inflammation by ultrasoundmediated gene transfer of Smad7 in rat remnant kidney. Kidney Int. Suppl. 67, S83-S91.

Nie, Y., Li, S., Yi, Y., Su, W., Chai, X., Jia, D., et al. (2014). Effects of astragalus injection on the TGFbeta/Smad pathway in the kidney in type 2 diabetic mice. BMC Complement Altern Med. 14:148.

Ohno, S. (1972). So much "junk" DNA in our genome. . Brookhaven Symp. Biol. 23, 366-370.

Pang, X., Feng, G., Shang, W., Liu, L., Li, J., Feng, Y., et al. (2019). Inhibition of IncRNA MEG3 protects renal tubular from hypoxia-induced kidney injury in acute renal allografts by regulating miR-181b/TNF- $\alpha$ signaling pathway. J. Cell. Biochem. 120, 12822-12831. doi: 10.1002/jcb.28553

Peng, W., Huang, S., Shen, L., Tang, Y., Li, H., and Shi, Y. (2019). Long noncoding RNA NONHSAG053901 promotes diabetic nephropathy via stimulating Egr1/TGF- $\beta$-mediated renal inflammation. J. Cell Physiol. 234, 18492-18503. doi: $10.1002 /$ jcp. 28485

Provenzano, M., Coppolino, G., De Nicola, L., Serra, R., Garofalo, C., Andreucci, M., et al. (2019). Unraveling cardiovascular risk in renal patients: a new take on old tale. Front. Cell Dev. Biol. 7:314. doi: 10.3389/fcell.2019. 00314

$\mathrm{Pu}, \mathrm{Y} ., \mathrm{Zhao}, \mathrm{H} ., \mathrm{Wu}, \mathrm{X} ., \mathrm{Mei}, \mathrm{M}$. , and Shen, B. (2020). The long noncoding RNA Ptprd-IR is a novel molecular target for TGF- $\beta 1$-mediated nephritis. Int. J. Biochem. Cell Biol. 122:105742. doi: 10.1016/j.biocel.2020.105742

Puthanveetil, P., Chen, S., Feng, B., Gautam, A., and Chakrabarti, S. (2015). Long non-coding RNA MALAT1 regulates hyperglycaemia induced inflammatory process in the endothelial cells. J. Cell. Mol. Med. 19, 1418-1425. doi: 10.1111/ jcmm. 12576

Quinn, J. J., and Chang, H. Y. (2016). Unique features of long non-coding RNA biogenesis and function. Nat. Rev. Genet. 17, 47-62. doi: 10.1038/nrg. 2015.10

Ren, G.-L., Zhu, J., Li, J., and Meng, X.-M. (2019). Noncoding RNAs in acute kidney injury. J. Cell. Physiol. 234, 2266-2276. doi: 10.1002/jcp.27203

Riaz, F., and Li, D. (2019). Non-coding RNA associated competitive endogenous rna regulatory network: novel therapeutic approach in liver fibrosis. Curr. Gene. Ther. 19, 305-317. doi: 10.2174/1566523219666191107113046 
Ruiz-Ortega, M., Rayego-Mateos, S., Lamas, S., Ortiz, A., and Rodrigues-Diez, R. R. (2020). Targeting the progression of chronic kidney disease. Nat. Rev. Nephrol. 16, 269-288.

Sarfi, M., Abbastabar, M., and Khalili, E. (2019). Long noncoding RNAs biomarkerbased cancer assessment. J. Cell Physiol. 234, 16971-16986. doi: 10.1002/jcp. 28417

Schiffer, M., Bitzer, M., Roberts, I. S., Kopp, J. B., Ten Dijke, P., Mundel, P., et al. (2001). Apoptosis in podocytes induced by TGF-beta and Smad7. J. Clin. Invest. 108, 807-816. doi: 10.1172/jci200112367

Schiffer, M., Schiffer, L. E., Gupta, A., Shaw, A. S., Roberts, I. S. D., Mundel, P., et al. (2002). Inhibitory smads and tgf-Beta signaling in glomerular cells. J. Am. Soc. Nephrol. JASN 13, 2657-2666. doi: 10.1097/01.asn.0000033276.06451.50

Sharma, K., Ix, J. H., Mathew, A. V., Cho, M., Pflueger, A., Dunn, S. R., et al. (2011). Pirfenidone for diabetic nephropathy. J. Am. Soc. Nephrol. JASN 22, 1144-1151.

Shen, J., Liu, L., Zhang, F., Gu, J., and Pan, G. (2019). LncRNA TapSAKI promotes inflammation injury in HK-2 cells and urine derived sepsis-induced kidney injury. J. Pharm. Pharmacol. 71, 839-848. doi: 10.1111/jphp.13049

Sun, J., Zhang, S., Shi, B., Zheng, D., and Shi, J. (2017). Transcriptome identified lncRNAs associated with renal fibrosis in UUO Rat Model. Front. Physiol. 8:658. doi: 10.3389/fphys.2017.00658

Sun, S. F., Tang, P. M. K., Feng, M., Xiao, J., Huang, X. R., Li, P., et al. (2018). Novel lncRNA Erbb4-IR promotes diabetic kidney injury in $\mathrm{db} / \mathrm{db}$ mice by targeting miR-29b. Diabetes 67, 731-744. doi: 10.2337/db17-0816

Tang, P. M., Tang, P. C., Chung, J. Y., and Lan, H. Y. (2017). TGF-betal signaling in kidney disease: from Smads to long non-coding RNAs. Noncoding RNA Res. 2, 68-73. doi: 10.1016/j.ncrna.2017.04.001

Tang, P. M., Zhang, Y. Y., and Lan, H. Y. (2018a). LncRNAs in TGF-beta-driven tissue fibrosis. Noncoding RNA 4:26. doi: 10.3390/ncrna4040026

Tang, P. M., Zhang, Y. Y., Mak, T. S., Tang, P. C., Huang, X. R., and Lan, H. Y. (2018b). Transforming growth factor-beta signalling in renal fibrosis: from Smads to non-coding RNAs. J. Physiol. 596, 3493-3503. doi: 10.1113/jp274492

Teng, K. Y., and Ghoshal, K. (2015). Role of Noncoding RNAs as biomarker and therapeutic targets for liver fibrosis. Gene. Expr. 16, 155-162. doi: 10.3727/ $105221615 \times 14399878166078$

Tian, H., Wu, M., Zhou, P., Huang, C., Ye, C., and Wang, L. (2018). The long non-coding RNA MALAT1 is increased in renal ischemia-reperfusion injury and inhibits hypoxia-induced inflammation. Renal. Failure 40, 527-533. doi: 10.1080/0886022x.2018.1487863

Trachtman, H., Fervenza, F. C., Gipson, D. S., Heering, P., Jayne, D. R., Peters, H., et al. (2011). A phase 1, single-dose study of fresolimumab, an anti-TGF-beta antibody, in treatment-resistant primary focal segmental glomerulosclerosis. Kidney Int. 79, 1236-1243. doi: 10.1038/ki.2011.33

Tsuchida, K., Zhu, Y., Siva, S., Dunn, S. R., and Sharma, K. (2003). Role of Smad4 on TGF-beta-induced extracellular matrix stimulation in mesangial cells. Kidney Int. 63, 2000-2009. doi: 10.1046/j.1523-1755.2003.00009.x

Van der Hauwaert, C., Glowacki, F., Pottier, N., and Cauffiez, C. (2019). NonCoding RNAs as new therapeutic targets in the context of renal fibrosis. Int. J. Mol. Sci. 20:1977. doi: 10.3390/ijms20081977

Vincenti, F., Fervenza, F. C., Campbell, K. N., Diaz, M., Gesualdo, L., Nelson, P., et al. (2017). A phase 2, double-blind, placebo-controlled, randomized study of fresolimumab in patients with steroid-resistant primary focal segmental glomerulosclerosis. Kidney Int. Rep. 2, 800-810. doi: 10.1016/j.ekir.2017.03.011

Voelker, J., Berg, P. H., Sheetz, M., Duffin, K., Shen, T., Moser, B., et al. (2017). Anti-TGF-betal antibody therapy in patients with diabetic nephropathy. J. Am. Soc. Nephrol. 28, 953-962. doi: 10.1681/asn.2015111230

Wang, C., Lu, T., Emanuel, G., Babcock, H. P., and Zhuang, X. (2019). Imagingbased pooled CRISPR screening reveals regulators of lncRNA localization. Proc. Natl. Acad. Sci. U.S.A. 116, 10842-10851. doi: 10.1073/pnas.1903808116

Wang, J., Pan, J., Li, H., Long, J., Fang, F., Chen, J., et al. (2018a). IncRNA ZEB1AS1 was suppressed by $\mathrm{p} 53$ for renal fibrosis in diabetic nephropathy. Mol. Ther. Nucleic Acids 12, 741-750. doi: 10.1016/j.omtn.2018.07.012

Wang, J., Song, J., Li, Y., Shao, J., Xie, Z., and Sun, K. (2020a). Down-regulation of LncRNA CRNDE aggravates kidney injury via increasing MiR-181a-5p in sepsis. Int. Immunopharmacol. 79:105933. doi: 10.1016/j.intimp.2019.105933

Wang, M., Wang, S., Yao, D., Yan, Q., and Lu, W. (2016a). A novel long noncoding RNA CYP4B1-PS1-001 regulates proliferation and fibrosis in diabetic nephropathy. Mol. Cell Endocrinol. 426, 136-145. doi: 10.1016/j.mce.2016. 02.020
Wang, M., Yao, D., Wang, S., Yan, Q., and Lu, W. (2016b). Long non-coding RNA ENSMUST00000147869 protects mesangial cells from proliferation and fibrosis induced by diabetic nephropathy. Endocrine 54, 81-92. doi: 10.1007/s12020016-0950-5

Wang, P., Luo, M. L., Song, E., Zhou, Z., Ma, T., Wang, J., et al. (2018b). Long noncoding RNA lnc-TSI inhibits renal fibrogenesis by negatively regulating the TGF-beta/Smad3 pathway. Sci. Transl. Med. 10:eaat2039. doi: 10.1126/ scitranslmed.aat2039

Wang, S., Chen, X., Wang, M., Yao, D., Chen, T., Yan, Q., et al. (2018c). Long noncoding RNA CYP4B1-PS1-001 inhibits proliferation and fibrosis in diabetic nephropathy by interacting with nucleolin. Cell Physiol. Biochem. 49, 21742187. doi: $10.1159 / 000493821$

Wang, W., Huang, X. R., Canlas, E., Oka, K., Truong, L. D., Deng, C., et al. (2006). Essential role of Smad3 in angiotensin II-induced vascular fibrosis. Circ. Res. 98, 1032-1039. doi: 10.1161/01.res.0000218782.52610.dc

Wang, Y. Y., Jiang, H., Pan, J., Huang, X. R., Wang, Y. C., Huang, H. F., et al. (2017). Macrophage-to-Myofibroblast transition contributes to interstitial fibrosis in chronic renal allograft injury. J. Am. Soc. Nephrol. 28, 2053-2067. doi: 10.1681/ asn.2016050573

Wang, Z., Zhang, B., Chen, Z., He, Y., Ru, F., Liu, P., et al. (2020b). The long noncoding RNA myocardial infarction-associated transcript modulates the epithelial-mesenchymal transition in renal interstitial fibrosis. Life Sci. 241:117187. doi: 10.1016/j.lfs.2019.117187

Wu, C. F., Chiang, W. C., Lai, C. F., Chang, F. C., Chen, Y. T., Chou, Y. H., et al. (2013). Transforming growth factor beta-1 stimulates profibrotic epithelial signaling to activate pericyte-myofibroblast transition in obstructive kidney fibrosis. Am. J. Pathol. 182, 118-131. doi: 10.1016/j.ajpath.2012. 09.009

Xiao, X., Yuan, Q., Chen, Y., Huang, Z., Fang, X., Zhang, H., et al. (2019). LncRNA ENST00000453774.1 contributes to oxidative stress defense dependent on autophagy mediation to reduce extracellular matrix and alleviate renal fibrosis. J. Cell. Physiol. 234, 9130-9143. doi: 10.1002/jcp.27590

Xie, H., Xue, J. D., Chao, F., Jin, Y. F., and Fu, Q. (2016). Long non-coding RNAH19 antagonism protects against renal fibrosis. Oncotarget 7, 51473-51481. doi: 10.18632/oncotarget.10444

Xu, B. H., Sheng, J., You, Y. K., Huang, X. R., Ma, R. C. W., Wang, Q., et al. (2020). Deletion of Smad3 prevents renal fibrosis and inflammation in type 2 diabetic nephropathy. Metabolism 103:154013. doi: 10.1016/j.metabol.2019.154013

Xue, L., Liu, L., Huang, J., Wen, J., Yang, R., Bo, L., et al. (2017). Tumor necrosis factor-like weak inducer of apoptosis activates type i interferon signals in lupus nephritis. Biomed. Res. Int. 2017:4927376.

Xue, R., Li, Y., Li, X., Ma, J., An, C., and Ma, Z. (2019). miR-185 affected the EMT, cell viability, and proliferation via DNMT1/MEG3 pathway in TGF- $\beta 1$-induced renal fibrosis. Cell Biol. Int. 43, 1152-1162. doi: 10.1002/cbin.11046

Yang, F., Chung, A. C., Huang, X. R., and Lan, H. Y. (2009). Angiotensin II induces connective tissue growth factor and collagen I expression via transforming growth factor-beta-dependent and -independent Smad pathways: the role of Smad3. Hypertension 54, 877-884. doi: 10.1161/hypertensionaha.109.136531

Yang, F., Huang, X. R., Chung, A. C., Hou, C. C., Lai, K. N., and Lan, H. Y. (2010). Essential role for Smad3 in angiotensin II-induced tubular epithelialmesenchymal transition. J. Pathol. 221, 390-401.

Yang, Y. L., Hu, F., Xue, M., Jia, Y. J., Zheng, Z. J., Li, Y., et al. (2019). Early growth response protein-1 upregulates long noncoding RNA Arid2-IR to promote extracellular matrix production in diabetic kidney disease. Am. J. Physiol. Cell Physiol. 316, C340-C352.

Yang, Y. L., Xue, M., Jia, Y. J., Hu, F., Zheng, Z. J., Wang, L., et al. (2020). Long noncoding RNA NEAT1 is involved in the protective effect of Klotho on renal tubular epithelial cells in diabetic kidney disease through the ERK1/2 signaling pathway. Exp. Mol. Med. 52, 266-280. doi: 10.1038/s12276-020-0381-5

Yao, L., Zhou, B., You, L., Hu, H., and Xie, R. (2020). LncRNA MIAT/miR-133a$3 p$ axis regulates atrial fibrillation and atrial fibrillation-induced myocardial fibrosis. Mol. Biol. Rep. 47, 2605-2617. doi: 10.1007/s11033-020-05347-0

Yi, H., Peng, R., Zhang, L. Y., Sun, Y., Peng, H. M., Liu, H. D., et al. (2017). LincRNA-Gm4419 knockdown ameliorates NF-кB/NLRP3 inflammasomemediated inflammation in diabetic nephropathy. Cell Death Dis. 8:e2583. doi: $10.1038 /$ cddis. 2016.451

Yoshimura, A., and Muto, G. (2011). TGF-beta function in immune suppression. Curr. Top Microbiol. Immunol. 350, 127-147. doi: 10.1007/82_2010_87 
Yuan, Q., Tan, R. J., and Liu, Y. (2019). Myofibroblast in kidney fibrosis: origin, activation, and regulation. Adv. Exp. Med. Biol. 1165, 253-283. doi: 10.1007/ 978-981-13-8871-2_12

Zeisberg, E. M., Potenta, S. E., Sugimoto, H., Zeisberg, M., and Kalluri, R. (2008). Fibroblasts in kidney fibrosis emerge via endothelial-to-mesenchymal transition. J. Am. Soc. Nephrol. 19, 2282-2287. doi: 10.1681/asn.2008050513

Zhang, C., Yuan, J., Hu, H., Chen, W., Liu, M., Zhang, J., et al. (2017a). Long noncoding RNA CHCHD4P4 promotes epithelial-mesenchymal transition and inhibits cell proliferation in calcium oxalate-induced kidney damage. Braz. J. Med. Biol. Res. 51:e6536.

Zhang, D., Liu, X., Wei, B., Qiao, G., Jiang, T., and Chen, Z. (2017b). Plasma lncRNA GAS8-AS1 as a potential biomarker of papillary thyroid carcinoma in chinese patients. Int. J. Endocrinol. 2017:2645904.

Zhang, J., Jiang, T., Liang, X., Shu, S., Xiang, X., Zhang, W., et al. (2019a). IncRNA MALAT1 mediated high glucose-induced HK-2 cell epithelial-to-mesenchymal transition and injury. J. Physiol. Biochem. 75, 443-452. doi: 10.1007/s13105019-00688-2

Zhang, K., Luo, Z., Zhang, Y., Zhang, L., Wu, L., Liu, L., et al. (2016). Circulating lncRNA H19 in plasma as a novel biomarker for breast cancer. Cancer Biomarkers 17, 187-194. doi: 10.3233/cbm-160630

Zhang, L., Zhao, S., and Zhu, Y. (2020a). Long noncoding RNA growth arrestspecific transcript 5 alleviates renal fibrosis in diabetic nephropathy by downregulating matrix metalloproteinase 9 through recruitment of enhancer of zeste homolog 2. Faseb J. 34, 2703-2714. doi: 10.1096/fj.201901380rr

Zhang, L. H., Xiao, B., Zhong, M., Li, Q., Chen, J. Y., Huang, J. R., et al. (2020b). LncRNA NEAT1 accelerates renal mesangial cell injury via modulating the miR-146b/TRAF6/NF-кB axis in lupus nephritis. Cell Tissue Res. 382, 627-638. doi: 10.1007/s00441-020-03248-Z

Zhang, P., Sun, Y., Peng, R., Chen, W., Fu, X., Zhang, L., et al. (2019b). Long non-coding RNA Rpph1 promotes inflammation and proliferation of mesangial cells in diabetic nephropathy via an interaction with Gal-3. Cell Death Dis. 10:526.

Zhang, T. N., Li, D., Xia, J., Wu, Q. J., Wen, R., Yang, N., et al. (2017c). Noncoding RNA: a potential biomarker and therapeutic target for sepsis. Oncotarget 8, 91765-91778. doi: 10.18632/oncotarget.21766

Zhang, Y., Meng, X. M., Huang, X. R., and Lan, H. Y. (2018). The preventive and therapeutic implication for renal fibrosis by targetting TGF-beta/Smad3 signaling. Clin. Sci. (Lond) 132, 1403-1415. doi: 10.1042/cs20180243

Zhang, Y. Y., Tang, P. M., Tang, P. C., Xiao, J., Huang, X. R., Yu, C., et al. (2019c). LRNA9884, a Novel Smad3-dependent long noncoding rna, promotes diabetic kidney injury in $\mathrm{db} / \mathrm{db}$ mice via enhancing MCP-1-dependent renal inflammation. Diabetes 68, 1485-1498. doi: 10.2337/db18-1075

Zhao, D., Liu, Z., and Zhang, H. (2019). The protective effect of the TUG1/miR-197/MAPK1 axis on lipopolysaccharide-induced podocyte injury. Mol. Med. Rep. 20, 49-56.
Zhao, T., Sun, S., Zhang, H., Huang, X., Yan, M., Dong, X., et al. (2016). Therapeutic effects of tangshen formula on diabetic nephropathy in rats. PLoS One 11:e0147693. doi: 10.1371/journal.pone.0147693

Zhao, T. T., Zhang, H. J., Lu, X. G., Huang, X. R., Zhang, W. K., Wang, H., et al. (2014). Chaihuang-Yishen granule inhibits diabetic kidney disease in rats through blocking TGF-beta/Smad3 signaling. PLoS One 9:e90807. doi: 10.1371/ journal.pone.0090807

Zhou, H., Gao, L., Yu, Z. H., Hong, S. J., Zhang, Z. W., and Qiu, Z. Z. (2019). LncRNA HOTAIR promotes renal interstitial fibrosis by regulating Notch1 pathway via the modulation of miR-124. Nephrology (Carlton) 24, 472-480. doi: $10.1111 /$ nep. 13394

Zhou, J., and Jiang, H. (2019). Livin is involved in TGF-beta1-induced renal tubular epithelial-mesenchymal transition through lncRNA-ATB. Ann. Transl. Med. 7:463. doi: 10.21037/atm.2019.08.29

Zhou, L., Fu, P., Huang, X. R., Liu, F., Chung, A. C., Lai, K. N., et al. (2010). Mechanism of chronic aristolochic acid nephropathy: role of Smad3. Am. J. Physiol. Renal. Physiol. 298, F1006-F1017.

Zhou, Q., Chung, A. C., Huang, X. R., Dong, Y., Yu, X., and Lan, H. Y. (2014). Identification of novel long noncoding RNAs associated with TGF-beta/Smad3mediated renal inflammation and fibrosis by RNA sequencing. Am. J. Pathol. 184, 409-417. doi: 10.1016/j.ajpath.2013.10.007

Zhou, Q., Huang, X. R., Yu, J., Yu, X., and Lan, H. Y. (2015a). Long Noncoding RNA Arid2-IR Is a novel therapeutic target for renal inflammation. Mol. Ther. 23, 1034-1043. doi: 10.1038/mt.2015.31

Zhou, Q., Xiong, Y., Huang, X. R., Tang, P., Yu, X., and Lan, H. Y. (2015b). Identification of genes associated with Smad3-dependent Renal Injury by RNAseq-based transcriptome analysis. Sci. Rep. 5:17901.

Zhou, S. G., Zhang, W., Ma, H. J., Guo, Z. Y., and Xu, Y. (2018). Silencing of LncRNA TCONS_00088786 reduces renal fibrosis through miR-132. Eur. Rev. Med. Pharmacol. Sci. 22, 166-173.

Zhu, Y., Ni, T., Lin, J., Zhang, C., Zheng, L., and Luo, M. (2019). Long non-coding RNA H19, a negative regulator of microRNA-148b-3p, participates in hypoxia stress in human hepatic sinusoidal endothelial cells via NOX4 and eNOS/NO signaling. Biochimie 163, 128-136. doi: 10.1016/j.biochi.2019.04.006

Conflict of Interest: The authors declare that the research was conducted in the absence of any commercial or financial relationships that could be construed as a potential conflict of interest.

Copyright (c) $2021 \mathrm{Gu}$, Dou, Huang, Liu and Lan. This is an open-access article distributed under the terms of the Creative Commons Attribution License (CC BY). The use, distribution or reproduction in other forums is permitted, provided the original author(s) and the copyright owner(s) are credited and that the original publication in this journal is cited, in accordance with accepted academic practice. No use, distribution or reproduction is permitted which does not comply with these terms. 